\title{
Analysis of Single Nucleic ACid Molecules With Protein Nanopores
}

\author{
Giovanni Maglia, Andrew J. Heron, David Stoddart, \\ Deanpen Japrung, and Hagan Bayley
}

\section{Contents}

1. Background: Analysis of Nucleic Acids with Nanopores

1.1. Structure of the $\alpha \mathrm{HL}$ nanopore

1.2. Nucleic acid analysis with $\alpha \mathrm{HL}$ nanopores

1.3. Homopolymeric strand analysis with protein nanopores

1.4. Recognition of specific sequences and single base mismatches through duplex formation

1.5. Individual base recognition by $\alpha \mathrm{HL}$ nanopores 597

1.6. Control of DNA translocation through nanopores 599

2. Electrical Recording with Planar Lipid Bilayers 601

2.1. Electrical recording equipment $\quad 602$

2.2. Faraday enclosure 603

2.3. Preparation of electrodes 603

2.4. Chambers 605

2.5. Preparing bilayers $\quad 606$

2.6. Inserting pores and adding DNA 609

2.7. Perfusion 610

3. Nanopores 610

3.1. Nanopore preparation $\quad 610$

3.2. Nanopore storage $\quad 610$

3.3. Measurements with nanopores 611

3.4. Nanopore stability $\quad 612$

4. Materials 613

4.1. Buffer components 613

4.2. Handling of DNA and RNA 613

4.3. Short single-stranded DNA or RNA 613

4.4. Long single-stranded DNA 614

4.5. Long RNA preparation $\quad 615$

4.6. Short dsDNA preparation $\quad 615$ 
5. Data Acquisition and Analysis $\quad 616$

5.1. Data digitization 616

5.2. Filtering and sampling $\quad 616$

$\begin{array}{ll}\text { 5.3. Acquisition protocols } & 617\end{array}$

5.4. Analysis of single DNA/RNA molecules 618

References $\quad 619$

\section{Abstract}

We describe the methods used in our laboratory for the analysis of single nucleic acid molecules with protein nanopores. The technical section is preceded by a review of the variety of experiments that can be done with protein nanopores. The end goal of much of this work is single-molecule DNA sequencing, although sequencing is not discussed explicitly here. The technical section covers the equipment required for nucleic acid analysis, the preparation and storage of the necessary materials, and aspects of signal processing and data analysis.

\section{NOMENCLATURE}

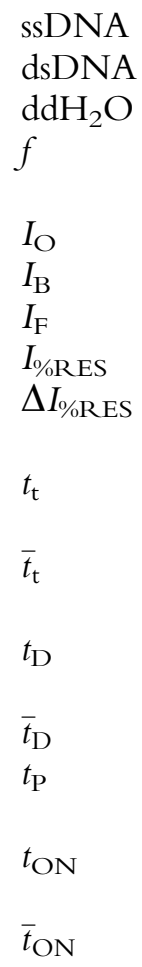

single-stranded DNA

double-stranded DNA

distilled, deionized water

normalized frequency of DNA interactions with pore (e.g., translocation events) in $\mathrm{s}^{-1} \mu M^{-1}$

open pore current

current through pore partially blocked by DNA

fractional residual current, that is, $I_{\mathrm{B}} / I_{\mathrm{O}}$

residual current as percentage of $I_{\mathrm{O}}$, that is, $I_{\mathrm{B}} / I_{\mathrm{O}} \times 100$

difference in $I_{\% \text { RES }}$ between residual currents (e.g., for two different DNAs)

time taken for translocation of an individual nucleic acid molecule

mean time taken for translocation of a nucleic acid molecule

dwell time of a nucleic acid molecule (not necessarily for a translocation event)

mean dwell time

most probable dwell time or translocation time taken from the peak of a dwell time or translocation time histogram interevent interval (e.g., time between translocation events)

mean interevent interval 


\section{BaCkground: Analysis of NuCleic ACIDS WITH NANOPORES}

Nanopores have been used to detect and analyze single molecules (Bayley and Cremer, 2001; Branton et al., 2008; Deamer and Branton, 2002; Dekker, 2007) and to investigate reaction mechanisms at the singlemolecule level (Bayley et al., 2008b). In this chapter, we focus on the analysis of nucleic acids with the protein pore formed by staphylococcal $\alpha$-hemolysin $(\alpha \mathrm{HL})$. First, we present background on the wide variety of experiments that can be performed on nucleic acids. Second, we enlarge on technical aspects of these experiments that have proved useful in our laboratory.

In a nanopore experiment, a single pore is located in a thin barrier that separates two compartments (henceforth called cis and trans) containing aqueous electrolyte. An electrical potential is applied across the barrier and the flow of ions through the nanopore is monitored. Molecules of interest are investigated by analyzing the associated modulation of the ionic current when the molecules pass through the pore or interact with the lumen (Fig. 22.1A). In this way, information about the length of nucleic acid

A

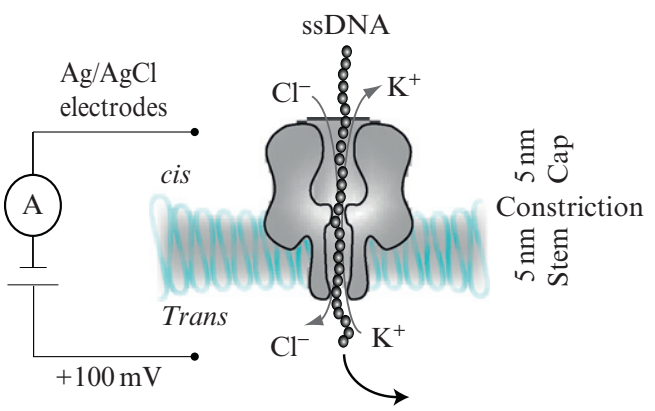

B

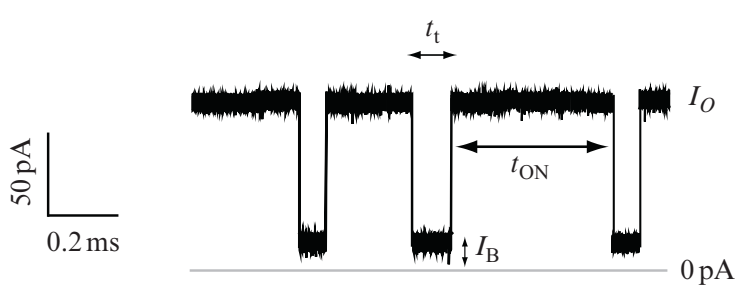

Figure 22.1 Nanopore analysis of DNA. (A) $\mathrm{Ag} / \mathrm{AgCl}$ electrodes are used to apply a potential (e.g., $+100 \mathrm{mV}$ ) to drive DNA through an $\alpha \mathrm{HL}$ nanopore embedded in a lipid bilayer and to measure the ionic current. (B) Typical trace for DNA translocating through a (wild-type) WT- $\alpha$ HL nanopore showing the translocation times $\left(t_{t}\right)$, the residual current values $\left(I_{\mathrm{B}}\right)$, and the interevent intervals $\left(t_{\mathrm{ON}}\right)$ for individual DNA translocation events. 
molecules and their base compositions is gathered. Duplex formation and dissociation, including unzipping in an applied potential, can be examined. The properties of enzymes and binding proteins associated with nucleic acids can also be determined. Stemming from this work, there is the potential to develop a cheap and fast technology to sequence single DNA molecules (Branton et al., 2008), but we do not emphasize this aspect here.

The two most common classes of nanopores are protein pores in lipid bilayers (Fig. 22.1) or synthetic nanopores formed in a variety of thin films, including Si-based materials, PDMS (polydimethylsiloxane), and polycarbonate (Dekker, 2007; Rhee and Burns, 2007; Sexton et al., 2007). Among the advantages of synthetic nanopores are that their dimensions can be adjusted during manufacture and that they can be produced as nanopore arrays. Protein nanopores also have significant advantages; in contrast with synthetic nanopores, their dimensions are reproducible and their structures can be precisely manipulated by site-directed mutagenesis and targeted chemical modification. The stability of solid-state pores in harsh environments is often mentioned as a key advantage, but it should be noted that the $\alpha \mathrm{HL}$ pore can withstand denaturants (Japrung et al., 2010), extremes of $\mathrm{pH}$ (Maglia et al., 2009b), and temperatures up to $\sim 95^{\circ} \mathrm{C}$ (Kang et al., 2005), conditions adequate for the analysis of DNA.

Although we focus on the analysis of nucleic acids with the $\alpha \mathrm{HL}$ nanopore, progress on DNA analysis with alternative protein pores is being made, notably with MspA from Mycobacterium smegmatis (Butler et al., 2008). The experimental principles developed for $\alpha \mathrm{HL}$ are valid in other cases.

\subsection{Structure of the $\alpha \mathrm{HL}$ nanopore}

$\alpha \mathrm{HL}$ is a heptameric protein that consists of a stem domain and a cap domain (Fig. 22.1) (Song et al., 1996). The stem domain comprises 14 antiparallel $\beta$ strands (two per protomer) that form a roughly cylindrical water-filled channel of $\sim 2 \mathrm{~nm}$ internal diameter. The internal cavity, or vestibule, within the cap domain is roughly spherical with an internal diameter of $\sim 4.5 \mathrm{~nm}$. The narrowest part of the interior of the pore is the constriction (1.4 $\mathrm{nm}$ in diameter), which is located between the cap and the stem domains. Under an applied potential, ions flow through the pore and the addition of single-stranded (ss)DNA to one side of the bilayer (typically the cis side) produces current blockades during the periods when a DNA molecule enters the pore (Fig. 22.1). Entry can result in a brief visit and then exit from the same side or translocation from the cis to the trans side of the bilayer. The dimensions of the pore are such that double-stranded (ds) DNA cannot pass through it (Kasianowicz et al., 1996), although dsDNA can penetrate as far as the constriction when presented from the cis side (Maglia et al., 2009b; Vercoutere et al., 2001). While we most often refer to DNA in this review, the same principles apply to RNA analysis. 


\subsection{Nucleic acid analysis with $\alpha \mathrm{HL}$ nanopores}

In electrical recordings from planar bilayers, it is important that sign conventions are followed consistently. We use the following. The cis chamber is that to which the protein nanopore is added; after insertion, the cap domain is exposed to the cis electrolyte. The cis chamber is at ground and the transmembrane potential is given as the potential on the trans side (i.e., the trans potential minus the cis potential; the latter is "zero" in the present case). A positive current is one in which positive charge (e.g., $\mathrm{K}^{+}$) moves through the pore from the trans to the cis side, or negative charge (e.g., $\mathrm{Cl}^{-}$) from the cis to the trans side.

The information that can be extracted from a typical electrical recording of DNA translocation through an $\alpha \mathrm{HL}$ nanopore is the mean translocation time $\left(\bar{t}_{\mathrm{t}}\right)$, the residual current level during translocation (I\%RES), and the mean interevent interval $\left(\bar{t}_{\mathrm{ON}}\right)$, which is the inverse of the frequency of events $(f)$, when $\bar{t}_{\mathrm{ON}} \gg \bar{t}_{\mathrm{t}}$ (Fig. 22.1B).

Translocation times of short single-stranded oligonucleotides $(<100$ nucleotides, nt) are described well by a Gaussian distribution with an exponential tail. The most probable translocation time $\left(t_{\mathrm{P}}\right)$ is given by the peak of the distribution (Meller et al., 2000). At $+120 \mathrm{mV}$ and $25^{\circ} \mathrm{C}$, the nucleic acid move through the pore at a speed of 1-22 $\mu$ s per nt $\left(t_{\mathrm{P}}\right.$ divided by the number of $\mathrm{nt}$ ). The speed depends on the base composition of the nucleic acid, with purine bases showing the shortest translocation times (Meller, 2003). In addition, $t_{\mathrm{P}}$ decreases exponentially with the temperature or the applied potential (Meller et al., 2000).

The frequency of occurrence of DNA translocation events increases with increased applied potential (Henrickson et al., 2000), temperature (Meller et al., 2000), or salt concentration (Bonthuis et al., 2006). In addition, a threshold potential must be exceeded to observe DNA capture (Henrickson et al., 2000) and even then capture is inefficient. Rough estimates suggest that, at voltages close to the threshold, about one DNA molecule in every 1000 that collide with the wild-type (WT)- $\alpha \mathrm{HL}$ pore is captured (Meller, 2003). By contrast, at the highest accessible applied potentials (around $+300 \mathrm{mV}$ ), $\sim 20 \%$ of the collisions result in DNA translocation (Nakane et al., 2002). However, the frequency of DNA capture can be improved by increasing the number of internal positive charges within the pore by site-directed mutagenesis, which also reduces the voltage threshold for DNA translocation through both the $\alpha \mathrm{HL}$ (Maglia et al., 2008) and MspA (Butler et al., 2008) nanopores. The most likely mechanisms for the increased frequency of translocation are a strengthened interaction when DNA molecules sample the interior of the pore, increased electroosmotic flow, or a combination of the two that depends on the applied potential (Maglia et al., 2008).

If nanopores are to be used to sequence DNA, single bases will most likely be identified at a recognition point within the nanopore by the extent 
to which they reduce the ionic current, rather than their dwell times (Bayley, 2006). Therefore, if a large current flows during DNA translocation $\left(I_{B}\right)$, the recognition of the bases is likely to be improved. The percent residual current $\left(I_{\% \text { RES }}=I_{\mathrm{B}} / I_{\mathrm{O}} \times 100\right)$ shows less experiment-to-experiment variation than the residual current $\left(I_{\mathrm{B}}\right)$ and therefore it is the descriptor of choice. $\Delta I_{\% \mathrm{RES}}$, the difference in $I_{\% \text { RES }}$ between residual currents (e.g., for two different DNAs), shows less variation still (Stoddart et al., 2010). WT- $\alpha$ HL nanopores generally show relatively low $I_{\%}$ Res values (typically $10 \%$ in $1 \mathrm{M} \mathrm{KCl}$, at $+120 \mathrm{mV}$ ), which depend on the nucleic acid used, with RNA generally blocking more current than DNA (Meller, 2003). $I_{\% \text { RES }}$ increases with increased applied potential (Stoddart et al., 2009) and decreased salt concentration (D. Stoddart, unpublished data). Recent studies have shown that $I_{\%}$ RES also depends on the amino acid side chains that project into the lumen of the pore (Maglia et al., 2008; Stoddart et al., 2009). At $+120 \mathrm{mV}$, additional positively charged residues in the barrel decrease $I_{\mathrm{B}}$ by $60-80 \%$ relative to WT- $\alpha \mathrm{HL}$ depending on the positioning of the charge (Maglia et al., 2008), while the elimination of ionic interactions and the reduction of side-chain volume at the constriction, in the mutant $\mathrm{E} 111 \mathrm{~N} / \mathrm{K} 147 \mathrm{~N}$, increase $I_{\mathrm{B}}$ by approximately twofold (Stoddart et al., 2009).

\subsection{Homopolymeric strand analysis with protein nanopores}

Homopolymeric ssDNA or ssRNA blockades can be discriminated with (wild-type) WT- $\alpha \mathrm{HL}$ nanopores by means of their residual currents $\left(I_{\mathrm{B}}\right)$ and translocation times $\left(t_{\mathrm{P}}\right)$. In $1 \mathrm{M} \mathrm{KCl}$ and at $+120 \mathrm{mV}$, poly-rA blockades show an $I_{\% \text { RES }}$ of $15 \%$ and a $t_{\mathrm{P}}$ value of $22 \mu$ s per nt, which are readily distinguished from poly-rC blockades $\left(I_{\% \text { RES }}=9 \%\right.$ and $5 \%$, and $t_{\mathrm{P}}=5.8 \mu \mathrm{s}$ per $\left.\mathrm{nt}\right)$ and from poly-rU blockades $\left(I_{\% \mathrm{RES}}=15 \%\right.$ and $t_{\mathrm{P}}=1.4 \mu$ s per nt) (Akeson et al., 1999). The DNAs, poly-dA and poly$\mathrm{dC}$, show different translocation times $\left(t_{\mathrm{P}}=1.9\right.$ and $0.8 \mu$ s per $\mathrm{nt}$, respectively), but similar $I_{\% \text { RES values }}(12.6 \%$ and $13.4 \%$, respectively) (Meller et al., 2000), while poly-dU shows longer blockades than both poly-dC and poly-dA (Butler et al., 2007). Although a fully convincing explanation has yet to be proposed, differences in translocation times and $I_{\mathrm{B}}$ value of homopolymeric strands through $\alpha \mathrm{HL}$ nanopores have been associated with differences in base pair-independent secondary structure including base stacking (Akeson et al., 1999; Meller et al., 2000).

The different extents of current blockade associated with homopolymeric RNA strands were exploited to detect the transition from poly-rA to poly-rC segments within the same molecule. When the translocation of poly- $r \mathrm{~A}_{30} \mathrm{C}_{70}$ through the WT- $\alpha \mathrm{HL}$ nanopore was investigated, $\sim 50 \%$ of the events exhibited current steps that reflected the transition (Akeson et al., 1999). 
The mean translocation speed is constant for short DNAs (from 12 to $100 \mathrm{nt}$ ) (Meller and Branton, 2002; Meller et al., 2001) and for poly-rU from 100 to 500 nt (Kasianowicz et al., 1996). For oligonucleotides shorter than the length of the barrel $(N<12)$, the translocation speed decreases with increasing nucleotide length in a nonlinear fashion. Polynucleotides longer than $500 \mathrm{nt}$ have not yet been carefully characterized.

\subsection{Recognition of specific sequences and single base mismatches through duplex formation}

$\alpha \mathrm{HL}$ pores have been used to recognize specific DNA sequences and single nucleotide mismatches through duplex formation. Howorka et al. (2001) covalently attached an 8-nt oligonucleotide within the vestibule of an $\alpha \mathrm{HL}$ pore. The complementary strand was then recognized by measuring the current blockade provoked by strand hybridization (Howorka et al., 2001). Single nucleotide mismatches were identified because they produced shorter current blockades. Based on duplex lifetimes, the DNA-nanopores were able to discriminate mismatches between the oligonucleotide tethered to the pore and complementary 8-base sequences within DNA strands of up to $30 \mathrm{nt}$. In addition, the last three bases in a 9-nt DNA attached to the pore were sequenced by the sequential addition of known oligonucleotides (Howorka et al., 2001). Vercoutere et al. (2001) detected single-base differences in short, blunt-ended DNA hairpin molecules with up to nine complementary bases. The entry of the hairpins into the vestibule of the $\alpha \mathrm{HL}$ pore was accompanied by a characteristic current blockade. Once in the vestibule, the hairpins spontaneously dissociated and a current spike signaled the translocation of the DNA strand through the pore. Single-base mismatches were detected by reduced duplex lifetimes, which reflected the stabilities of the duplexes in solution (Vercoutere et al., 2001). Nakane et al. (2004) used streptavidin to immobilize a biotinylated probe DNA molecule within the $\alpha \mathrm{HL}$ pore (Fig. 22.2). The untethered end of the DNA strand entered the trans compartment at positive potentials, where it bound a complementary oligonucleotide to form a rotaxane. Reversal of the applied potential exerted a force on the duplex. A shorter mean time for dissociation by comparison with the value for a fully complementary pair was used to recognize single mismatches in probe-oligonucleotide duplexes (Nakane et al., 2004).

\subsection{Individual base recognition by $\alpha \mathrm{HL}$ nanopores}

The recognition of individual DNA bases during translocation is crucial if the sequencing of DNA molecules is to be achieved by using nanopores. However, at present, the translocation of nucleic acids through $\alpha \mathrm{HL}$ nanopores is so rapid (1-22 $\mu$ s per nt) that only artificially bulky bases 

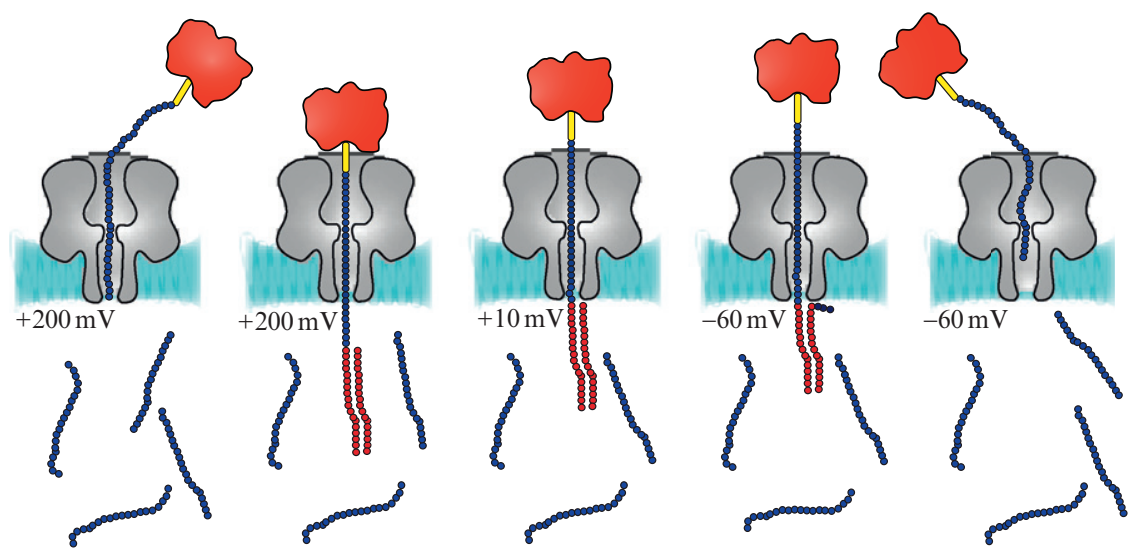

Figure 22.2 Detection of an ssDNA by hybridization. From left to right: A high applied potential (e.g., $+200 \mathrm{mV}$ ) is used to capture a biotinylated DNA probe (complexed with streptavidin) within the $\alpha \mathrm{HL}$ pore. The target DNA strand emerges on the opposite side of the bilayer where it forms a duplex, if it is recognized by a complementary strand. The voltage is lowered to $+10 \mathrm{mV}$. If a duplex has been formed, the probe DNA remains in the pore as a rotaxane. If a duplex has not formed, the probe DNA escapes under the low applied potential. To measure the strength of the duplex, eject the probe DNA and begin a new cycle, the applied potential is stepped to $-60 \mathrm{mV}$.

(Mitchell and Howorka, 2008) or the transition between homopolymer stretches of $\sim 30 \mathrm{nt}$ can be detected (Akeson et al., 1999). Therefore, to test the feasibility of base detection, DNA strands have been immobilized within the $\alpha \mathrm{HL}$ pore by using terminal hairpins (Ashkenasy et al., 2005) (Fig. 22.3C). Because the hairpin might interfere with recognition (Fig. 22.3A), recent work has exploited the interaction between a biotinylated oligonucleotide and streptavidin to immobilize DNA strands (Purnell and Schmidt, 2009; Stoddart et al., 2009) (Fig. 22.3B). In our work, the ability of the $\alpha \mathrm{HL}$ pore to discriminate individual bases was investigated by sampling several DNA molecules in which the position of a single base was altered in an otherwise identical homopolymeric background (Fig. 22.3C). While Ghadiri and coworkers were able to identify a recognition point at the trans entrance of the $\alpha \mathrm{HL}$ nanopore that could discriminate a single $\mathrm{dA}$ in a poly-dC background (Ashkenasy et al., 2005), the biotinylated oligonucleotides were used to sample the entire length of the pore (Stoddart et al., 2009). $\alpha \mathrm{HL}$ was found to contain three broad recognition sites. When an engineered pore (E111N/K147N) was used, with enhanced current flow when DNA occupies the pore $\left(I_{\mathrm{B}}\right)$, all four DNA bases could be distinguished in a poly-dC background. Individual base differences could also be detected in a heteropolymeric DNA strand (Stoddart et al., 2009). 
A

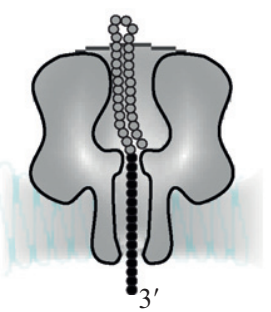

C

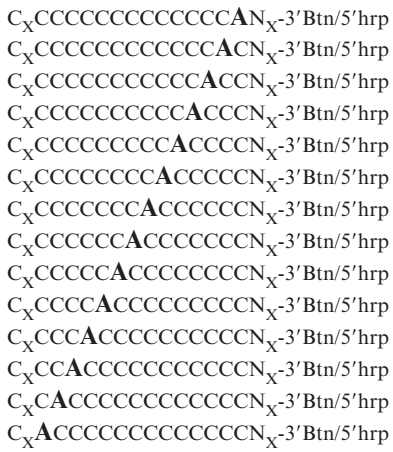

B

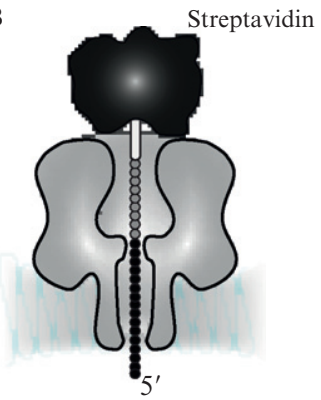

Figure 22.3 Single base recognition in immobilized DNA strands. (A) The translocation of a DNA strand can be arrested by using a terminal DNA hairpin. (B) Alternatively, the translocation of a biotinylated DNA strand can be halted by preincubating the ssDNA with streptavidin. The grey circles indicate the DNA that is in the vestibule and the black circles are the DNA bases that span the barrel of the pore. (C) The barrel of the pore can be sampled by measuring the current blockades provoked by DNA sequences in which the location of a single base is moved within an otherwise identical background. Hrp, hairpin; Btn, biotinylated linker; $\mathrm{N}_{\mathrm{X}}$, nucleotides that are in the vestibule of the pore; $\mathrm{C}_{\mathrm{X}}$, nucleotides that protrude through the trans entrance of the pore.

\subsection{Control of DNA translocation through nanopores}

Controlling the speed at which DNA translocates through a pore is perhaps the single most important challenge that has to be overcome in nanopore sequencing (Branton et al., 2008). At high sampling rates, noise levels are too high for base discrimination. A recent paper estimates that $98 \%$ of the small current differences observed for the four DNA nucleotides could be discriminated by an $\alpha \mathrm{HL}$ nanopore assuming a mean dwell time of $10 \mathrm{~ms}$ (Clarke et al., 2009), but this is at least 3 orders of magnitude longer than the transit time for individual bases in freely translocating ssDNA. Several attempts have been made to reduce the DNA translocation speed. For example, it has been shown recently that increasing the viscosity of the 
sample solution by adding $63 \%$ (v/v) glycerol to the aqueous electrolyte can slow down DNA translocation through $\alpha \mathrm{HL}$ nanopores by more than an order of magnitude, but at the expense of a 10-fold decrease in the unitary conductance of the pore (Kawano et al., 2009). In efforts to increase the local viscosity, but preserve the conductance of the pore, a positively charged dendrimer with a hydrodynamic volume of $4.2 \mathrm{~nm}$ (Martin et al., 2007) and uncharged PEG molecules of similar size (G. Maglia, unpublished data) were covalently attached inside the vestibule of the $\alpha \mathrm{HL}$ pore. The modified nanopores showed a conductance that was roughly half that of the WT $-\alpha$ HL pore. However, both polymers almost completely inhibited the passage of nucleic acids through the pore, rather than slow their movement. Attempts to engineer the internal positive charge of the $\alpha \mathrm{HL}$ pore to form "molecular brakes" to reduce the speed of ssDNA translocation have also been made (Rincon-Restrepo, in preparation). Modified versions of the pore were prepared with up to seven internal rings of seven arginine residues. Although the translocation speed was reduced by more than 2 orders of magnitude, the resulting $I_{\mathrm{B}}$ values were too low to allow for discrimination of individual bases. Optical and magnetic traps have also been used to move DNA strands through solid-state nanopores (Keyser et al., 2006; Peng and Ling, 2009), but so far these have been long doublestranded DNAs. Due to the instability of the lipid bilayer and the diffusion of nanopores within it, these techniques cannot be easily implemented with biological nanopores.

Ultimately, DNA-processing enzymes will most likely be used to control DNA translocation through biological pores. ExoI-ssDNA complexes gave current blockades that were approximately fivefold longer and showed a higher $I_{\mathrm{B}}$ value than the current blockades produced by free ssDNA under the same conditions $(+180 \mathrm{mV}, 1 \mathrm{M} \mathrm{KCl})$ (Hornblower et al., 2007). The disappearance of the long current blockades after the addition of $\mathrm{Mg}^{2+}$, which triggers the activity of the enzyme, confirmed that these blockades were due to DNA in ExoI-ssDNA complexes entering the nanopore. But, the enzymatically driven movement of DNA was not demonstrated in this work. In a similar approach, the interaction of RNA with the $\alpha \mathrm{HL}$ pore was monitored in the presence of P4 ATPase, a motor protein from bacteriophage $\phi 8$, but again the movement of the nucleic acid could not be shown (Astier et al., 2007). Recently, the activity of a DNA polymerase was monitored with single base resolution by using an $\alpha \mathrm{HL}$ nanopore (Cockroft et al., 2008). A DNA strand was immobilized within the pore by threading a streptavidin - biotin-phosphoPEG-ssDNA complex through the trans entrance under a negative potential (Fig. 22.4). DNA primers (to form a rotaxane) and TopoTaq DNA polymerase were then added to the cis side and single-nucleotide primer extensions were identified by the current changes caused by the movement of phosphoPEG into the barrel of the pore after the addition of dNTPs (Fig. 22.4). Up to nine successive steps were 

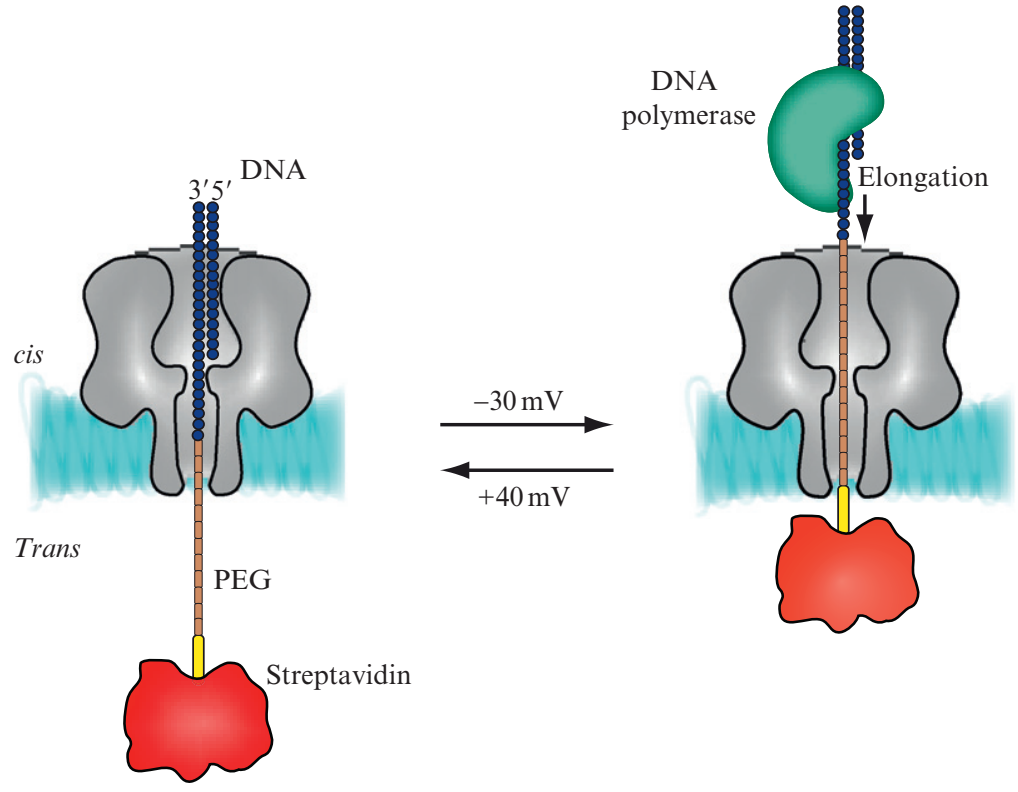

Figure 22.4 Single nucleotide extension monitored with a protein nanopore. (Left) The monitoring configuration. A phosphoPEG sequence occupies a fraction of the barrel of the $\alpha \mathrm{HL}$ pore and modulates the ionic current to a level that depends on the extent to which the primer has been elongated. (Right) Elongation configuration. dsDNA is accessible to the DNA polymerase. Elongation by a single nucleotide is controlled by the identity of the dNTPs in solution. The activity of the DNA polymerase can be monitored by stepping the potential between +40 and $-30 \mathrm{mV}$.

observed by switching the potential between $-30 \mathrm{mV}$ (a potential at which elongation was possible) and $+40 \mathrm{mV}$ (the potential used to monitor the elongation steps). Future efforts will be directed toward combining such an elongation device with an engineered $\alpha \mathrm{HL}$ pore capable of base identification.

\section{Electrical Recording with Planar Lipid BILAYERS}

Protein nanopores employed for DNA analysis must be reconstituted into artificial bilayers that mimic biological membranes. We carry out our experiments with planar lipid bilayers, examining single pore under in vitro conditions where all the constituents of the system are carefully controlled. "Single-channel" experiments require sensitive equipment to measure the small currents passed by individual protein pores. There is a wealth of good literature detailing the various aspects of setting up such equipment and 
carrying out experiments on single protein channels and pores (see, e.g., The Axon Guide: www.moleculardevices.com/pages/instruments/axon_guide. html) (Hanke and Schlue, 1993; Miller, 1986; Sakmann and Neher, 1995), so here we just cover the specific apparatus and procedures employed in our laboratory for examining the interaction of DNA with the $\alpha \mathrm{HL}$ pore.

\subsection{Electrical recording equipment}

Single-channel electrical measurements can be carried out with a range of equipment, both commercial and custom built. We use Axopatch 200B patch-clamp amplifiers (Molecular Devices) with 16-bit digitizers (132x or 1440A, Molecular Devices). DNA measurements are typically acquired in voltage-clamp mode using resistive WHOLE-CELL $(\beta=1)$ headstage settings. In voltage-clamp mode, the applied voltage is fixed, and the transmembrane current required to maintain that voltage is measured. Voltage clamping does not mimic a process found in nature, but many of the interactions of DNA with the $\alpha \mathrm{HL}$ pore are voltage dependent, so it is imperative to control the applied potential. Furthermore, in this mode no capacitive transients are produced (except when changing the applied voltage), and the current flow is proportional to the conductance of the channels.

The Axopatch 200B has a recording bandwidth of $100 \mathrm{kHz}$, and the digitizers have a maximum sampling rate of $250 \mathrm{kHz}$ per channel, which determines the maximum temporal resolution $(4 \mu \mathrm{s})$. Amplitude resolution is primarily limited by the noise in the system. Planar bilayers are prone to relatively high background current noise (e.g., $>1$ pA RMS at $10 \mathrm{kHz}$ ) that can obscure small current steps (The Axon Guide) (Mayer et al., 2003; Wonderlin et al., 1990). Signal-to-noise can be improved by applying lowpass filtering, at the expense of a loss of temporal resolution. Therefore, although the electronics can acquire in the microsecond regime (freely translocating nucleic acids pass at $\sim 1-22 \mu$ s per nt), in practice there is a balance between acquiring fast enough to observe the events of interest, and low-pass filtering to observe small amplitude current differences.

There are three main sources of internal noise in a planar bilayer system, in increasing order of magnitude (The Axon Guide) (Mayer et al., 2003; Wonderlin et al., 1990): (1) noise originating in the acquisition electronics, (2) noise from clamping the thermal voltage noise in the access resistance (i.e., the resistance of the solutions and electrodes in series with the bilayer) across a large capacitance bilayer, and (3) noise from the nanopore itself. There are various strategies for reducing noise that are well covered in the literature (The Axon Guide) (Mayer et al., 2003; Wonderlin et al., 1990). Access resistance can account for substantial noise in planar bilayer systems in the absence of a pore (Wonderlin et al., 1990). The access resistance can be reduced by: (1) using higher salt solutions in the cis and trans compartments, (2) using larger area electrodes, and (3) reducing the resistance of the agar 
bridges (discussed below). The use of suitable aperture materials is also important for reducing dielectric noise (e.g., PTFE films produce lower noise than some other plastics; Mayer et al., 2003; Wonderlin et al., 1990). However, the single most effective means of reducing noise in the absence of a pore is to reduce the size of the bilayer and hence its capacitance (The Axon Guide) (Mayer et al., 2003; Wonderlin et al., 1990). Nevertheless, in practice, the largest source of noise is from the protein pore itself. Protein-derived noise arises from extremely fast fluctuations in conformation and charge states inside a pore (Bezrukov and Kasianowicz, 1993; Korchev et al., 1997). The noise is dependent on physical conditions ( $\mathrm{pH}$, temperature, salt concentration, etc.), and for $\alpha \mathrm{HL}$ we typically observe RMS noise that is two to three times greater than the noise from the bilayer alone.

\subsection{Faraday enclosure}

Electrical recording experiments should be carried out in a conducting enclosure (a Faraday cage) to shield the sensitive acquisition electronics from external radiative electrical noise. We typically use steel or aluminum boxes $\sim 50 \times 50 \times 50 \mathrm{~cm}$ in dimensions with rigid side walls $>1 \mathrm{~mm}$ thick. The boxes are grounded via the common ground in the patch-clamp amplifier (www.moleculardevices.com). Vibration isolation is an important consideration (The Axon Guide). External noise (e.g., from heavy machinery) can be transmitted through a laboratory bench into the box and result in substantial noise in the signal. Therefore, we mount our Faraday cages on pneumatic antivibration tables or soft supports (e.g., partially inflated soft rubber tubing). Unfortunately, antivibration tables do little to prevent sensitivity to environmental noise (i.e., loud noises, or even talking), as the large surfaces of the boxes pick up vibrations in the air. Although the Faraday cage might be housed inside an acoustically isolated enclosure, this source of noise can simply be eliminated by using a Faraday cage with stiff or absorbent walls that are well damped against vibrations. Finally, it is essential that the electrodes within the box are: (1) as short as possible (to reduce access resistance, input capacitance, and the reception of radiated noise) and (2) firmly secured to prevent their vibration.

While a Faraday cage is effective at isolating the system from external noise, care must be taken not to introduce internal sources of noise. As a result, any internal equipment (e.g., stirrers, peltier heaters, etc.) needs to be carefully shielded and should ideally run off a DC battery inside the Faraday cage.

\subsection{Preparation of electrodes}

$\mathrm{Ag} / \mathrm{AgCl}$ electrodes are most commonly employed in bilayer recording due to their long-term chemical stability, reversible electrochemical behavior, predictable junction potentials, and superior low-noise electrical performance. 
However, it should be noted that $\mathrm{Ag} / \mathrm{AgCl}$ electrodes only perform well in solutions containing chloride ions. For experiments involving asymmetric solutions (where the chambers contain chloride ions at different concentrations), agar bridges (as discussed later) are used to prevent substantial liquid junction potential offsets (The Axon Guide).

$\mathrm{Ag} / \mathrm{AgCl}$ electrodes are typically prepared from $\mathrm{Ag}$ wire by either: (1) electroplating in $\mathrm{HCl}$ solution, (2) dipping in molten $\mathrm{AgCl}$, or (3) treatment with a weak hypochlorite solution (The Axon Guide) (Purves, 1981). Our preferred approach is an overnight treatment with hypochlorite, as this produces long lasting electrodes with a thick coating of $\mathrm{AgCl}$. We make our electrodes from $1.5 \mathrm{~mm}$ diameter silver wire $(>99.99 \%$, SigmaAldrich), using lengths of $\sim 10 \mathrm{~mm}$ (Fig. 22.5). These electrodes have a large reactive surface area, which prolongs their working life and minimizes the access resistance. Before treatment, the electrodes are thoroughly cleaned and roughened by abrasion (e.g., with a wire brush or glass paper), and then immersed in $1-5 \%$ (w/v) $\mathrm{NaClO}$ (Fisher Scientific) in water. After treatment, the electrodes are rinsed with distilled water. The electrodes are prepared and stored in the dark to prevent UV conversion of $\mathrm{AgCl}$ back to $\mathrm{Ag}$. In our experience, good electrodes have a rough texture and a dull gray color (Fig. 22.5).

The use of a $3 \mathrm{M} \mathrm{KCl} /$ agar bridge between an electrode and the chamber solution is recommended for all experiments, but in particular for experiments carried out under asymmetric salt conditions to reduce junction potential offsets. The $3 \mathrm{M} \mathrm{KCl}$ filling solution also reduces the access resistance. Another advantage of the agar bridge is that it prevents $\mathrm{Ag}^{+}$ions from the electrode leaching into the solution, which can adversely affect the activity of some protein pores. To create the agar bridges, we incorporate our $1.5 \mathrm{~mm} \mathrm{Ag/AgCl}$ electrodes into $200 \mu$ pipette tips (Gilson, USA) filled with (initially) molten agar (3\% (w/v) low melt agarose
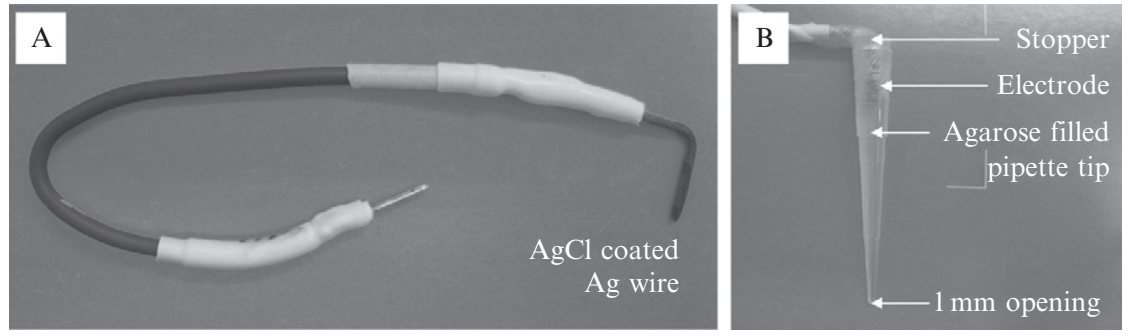

Figure 22.5 $\mathrm{Ag} / \mathrm{AgCl}$ electrodes. (A) Photograph of an $\mathrm{Ag} / \mathrm{AgCl}$ electrode, prepared by hypochlorite treatment of a short piece $(\sim 10 \mathrm{~mm})$ of $1.5 \mathrm{~mm}$-diameter Ag wire (soldered onto standard electrical wire). (B) To make agar bridges, we incorporate our electrodes into $200 \mu \mathrm{l}$ pipette tips filled with agar $(3 \%$, w/v, $3 \mathrm{M} \mathrm{KCl}$ in unbuffered $\mathrm{ddH}_{2} \mathrm{O}$ ), sealing the top with a rubber stopper and parafilm. 
in $3 \mathrm{M} \mathrm{KCl}$ in pure water), with a rubber stopper as a seal (Fig. 22.5). In addition, the opening of the pipet connecting to the bulk chamber solution should not be too small (we recommend an opening of $>1 \mathrm{~mm}$ diameter).

Immediately before use, the electrodes are electrically balanced in symmetric solutions of the experimental buffer (e.g., $1 \mathrm{M} \mathrm{KCl}, 25 \mathrm{mM}$ Tris- $\mathrm{HCl}, \mathrm{pH} 8.0$ ) by using the pipet offset function on the patch-clamp amplifier. Little to no potential adjustment is required for good electrodes. A sign of poor or degraded electrodes is the development of white patches and a requirement to rebalance the potential offset.

\subsection{Chambers}

We use open planar bilayer chambers for the majority of our DNA experiments. However, in some cases, in particular where limited quantities of reagents are available, we also make use of droplet interface bilayers that have solution volumes of $<200 \mathrm{nl}$ (Bayley et al., 2008a). Open chambers come in a wide variety of shapes and formats, with vertical or horizontal bilayers and solution volumes ranging from $50 \mu \mathrm{l}$ to $1 \mathrm{ml}$. Although commercial options are available (e.g., Warner Instruments), we use custom vertical bilayer devices machined from Delrin (Fig. 22.6), where the two compartments of $0.5-1.0 \mathrm{ml}$ are separated by a $20 \mu \mathrm{m}$-thick PTFE film (Goodfellow, UK). In this format, both the cis and trans solutions are easily accessed for the purposes of adding reagents or perfusion.
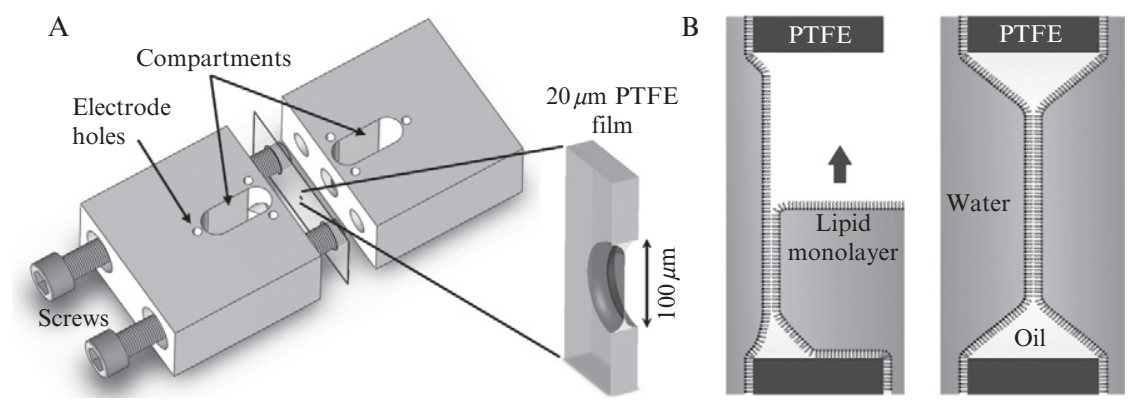

Figure 22.6 Planar bilayer formation. (A) We use custom vertical planar bilayer chambers, with two $1 \mathrm{ml}$ compartments separated by a $20-\mu \mathrm{m}$ PTFE film, shown here in an exploded view. The two halves are fastened together with screws, clamping the PTFE film between them. The apparatus is sealed with silicone glue (Sylgard 184, Dow Corning) to ensure water-tightness. The PTFE film contains a central aperture $\sim 100 \mu \mathrm{m}$ diameter, across which the bilayer is formed. (B) The bilayer is formed by the Montal-Mueller method. The aperture is pretreated with an oil (e.g., hexadecane), and the bilayer is then formed by flowing Langmuir-Blodgett lipid monolayers over both sides of the aperture. 
The only path between the two compartments is a central aperture in the PTFE film across which the bilayer is formed (Fig. 22.6A, enlargement). The diameter depends on the size of bilayer required, and is typically $\sim 100 \mu \mathrm{m}$. While there are many approaches for producing small apertures (Wonderlin et al., 1990), we favor "zapping" the films with a custom high-voltage spark generator (producing a spark $\sim 15 \mathrm{~mm}$ long at a frequency of $\sim 1 \mathrm{~Hz}$ ). Commercial products are available (e.g., Daedelon, USA). To control the location of the aperture, the Teflon film is weakened at the desired point by gently indenting with a sharp needle. The spark passes through this weakness, and the high temperature causes localized melting, which produces a perfectly round aperture. The aperture is sparked several times until the desired diameter is achieved (as measured under a microscope with a graticule). This technique produces high quality apertures with reproducible dimensions (typically $>50$ and $\pm 10 \mu \mathrm{m}$ ) (Mayer et al., 2003).

Reducing bilayer size, and hence capacitance, reduces noise. However, this must be balanced against the practical necessity of creating bilayers reproducibly (bilayers that are too small are often occluded by enlargement of the annulus) and the difficulty of inserting channels into overly small bilayers. A good compromise is to use bilayers with a capacitance of $\sim 60-100 \mathrm{pF}$, which corresponds to a diameter of $\sim 105-135 \mu \mathrm{m}$ (DPhPC/hexadecane, assuming a specific capacitance of $0.70 \mu \mathrm{F} \mathrm{cm}{ }^{-2}$; Peterman et al., 2002).

\subsection{Preparing bilayers}

Planar bilayers are typically created across small apertures in a plastic film by variants of two main approaches (White, 1986). In the first, the bilayer is created by directly painting a lipid/oil solution (e.g., $5 \%$ (w/v) of DPhPC in hexadecane) around the aperture before adding the aqueous solution. This thick lipid/oil film spontaneously thins and after a few minutes forms a bilayer due to Plateau-Gibbs suction (Niles et al., 1988). In the second approach, the aperture is first pretreated with the oil (e.g., hexadecane), and then the bilayer is formed by flowing Langmuir-Blodgett lipid monolayers across both sides of the aperture (Fig. 22.6B) (Montal and Mueller, 1972; White et al., 1976). In both approaches, the oil (generally an $n$-alkane such as decane or hexadecane) is extremely important, as it creates an annulus around the rim of the aperture, which allows the bilayer to form an interface with the plastic film (Plateau-Gibbs border). We favor the second "MontalMueller" approach. The primary advantages of this technique are that the bilayers are quick to form (with the painting approach it can take tens of minutes for the bilayer to spontaneously thin), and asymmetric bilayers can be created if the two compartments contain lipids of a different composition. 
Briefly, we pretreat the aperture with hexadecane by the direct application of a single drop $(\sim 5 \mu \mathrm{l})$ of $10 \%(\mathrm{v} / \mathrm{v})$ hexadecane in pentane. After the pentane has evaporated, both compartments of the chamber are filled with the buffered aqueous electrolyte and the electrodes are connected. The aperture should be free of excess oil, so that an electrical current can be measured between the compartments. (At zero applied potential on the amplifier, there remains a very small potential difference between the compartments.) In the case of blockage, excess oil can be removed by gently pipetting solution at the aperture. A small drop $(\sim 5 \mu \mathrm{l})$ of lipid in pentane solution (e.g., DPhPC, $\left.10 \mathrm{mg} \mathrm{ml}^{-1}\right)$ is then applied directly to the top of the aqueous phase. After waiting $\sim 1 \mathrm{~min}$ for the pentane to evaporate fully, solution is pipetted from the bottom of a compartment to lower the lipid monolayer at the water-air interface past the aperture level. The solution level is then slowly raised back above the aperture. After repeating this procedure several times in each compartment, a bilayer forms, and the electrical current drops to zero. We measure the capacitance, as described later, to judge the size and quality of the bilayer.

We use DPhPC bilayers with hexadecane as the oil in most of our studies. DPhPC has ideal bilayer forming properties. It exists in the fluid lamellar phase across a wide temperature range $\left(-120\right.$ to $\left.+120^{\circ} \mathrm{C}\right)$ (Hung et al., 2000; Lindsey et al., 1979), and it is stable to oxidation. Planar bilayers can, however, be prepared from a wide range of phospholipids or phospholipid mixtures. These can have zwitterionic or charged headgroups, and may contain additives such as cholesterol. The correct lipid mixture may be essential for certain proteins to function (e.g., mechano-sensitive channels; Phillips et al., 2009). The phospholipid mixture usually, but not always (Krasne et al., 1971), has fluid lamellar properties under the conditions of the experiment. Many oils can be used to interface the bilayer with the aperture (n-alkanes, squalene, etc.), but experimentalists should be aware that the shorter chain $n$-alkanes (e.g., decane) interdigitate into the bilayer leading to increased bilayer thickness (White, 1975, 1986). Although this is not important for a robust pore such as $\alpha \mathrm{HL}$, bilayer thickness differences can affect the properties of membrane proteins (Phillips et al., 2009). Hexadecane produces bilayers with little oil content (White, 1975, 1986).

A standard cleaning routine is used between experiments: first rinsing with large amounts of water, then repeated steps of distilled water rinses followed by $100 \%$ ethanol rinses. Finally, the chambers are thoroughly dried under a stream of nitrogen. When required, we also employ detergent washing steps, $\mathrm{NaOH}(1 M)$ or $\mathrm{HCl}(1 M)$ washes, or rinsing with an EDTA solution (e.g., $10 \mathrm{mM}$ ) to remove traces of divalent metal ions.

\subsubsection{Bilayer stability}

The planar bilayers we have described typically have lifetimes of a few hours and can withstand constant applied potentials of 200-300 mV. Smaller bilayers $(<100 \mu \mathrm{m}$ diameter $)$ are much less susceptible to pressure variations 
and mechanical shock, and are therefore longer lived. DPhPC bilayers are stable up to $\sim 100{ }^{\circ} \mathrm{C}$ (Kang et al., 2005). In certain cases, alternative oils should be used. For example, hexadecane is frozen below $18{ }^{\circ} \mathrm{C}$, and hexadecene or shorter chains alkanes can be employed at low temperatures. Planar bilayers are also able to withstand substantial osmotic gradients arising from the use of asymmetric salt conditions (we often use asymmetric solutions of $150 \mathrm{mM} / 1 \mathrm{M}$ salt to measure ionic charge selectivity), although the solutions can be balanced if instability occurs by the addition of an osmolyte (e.g., sucrose) to the low-salt compartment.

\subsubsection{Measuring bilayer capacitance}

It is important to measure bilayer capacitance, because pores will not insert into misformed bilayers. There are a number of ways of determining capacitance (for reviews see Gillis, 1995; Kado, 1993). One of the most versatile and straightforward is the application of voltage ramps to elicit constant capacitive currents (Fig. 22.7). Since current $(I)$ is proportional to the rate of change of voltage $(\mathrm{d} V / \mathrm{d} t)$ for a capacitor $(I=C \times \mathrm{d} V / \mathrm{d} t)$, an applied triangular voltage waveform produces a square-wave current output (i.e., $\mathrm{d} V / \mathrm{d} t=$ constant, for each sweep), which can be used to determine bilayer capacitance (Fig. 22.7). We use commercial analog waveform generators, inputting a triangular wave $(\sim 20 \mathrm{~Hz})$ into the patch-clamp amplifier (front-switched input on an Axopatch 200B amplifier). We directly calibrate the input waveform by using a $100 \mathrm{pF}$ bilayer model cell (MCB-1U, Molecular Devices), so that $100 \mathrm{pA}=100 \mathrm{pF}$. This approach provides a visual measurement of capacitance, which is useful

A
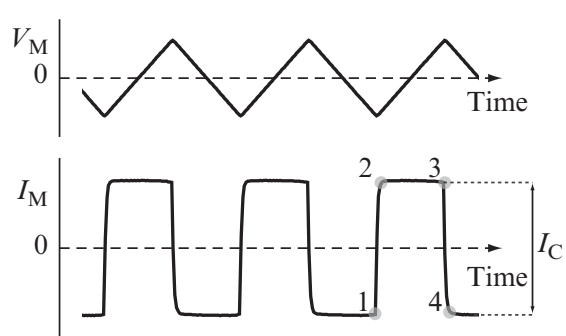

Ideal bilayer
B
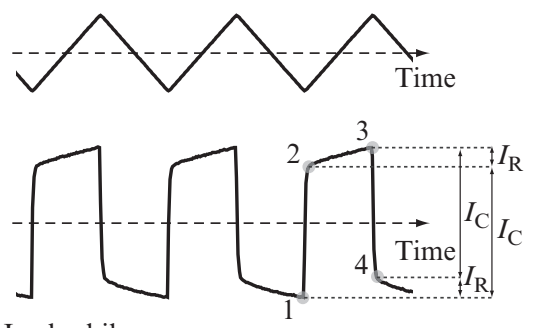

Leaky bilayer

Figure 22.7 Measuring bilayer capacitance. A triangular-wave voltage input applied across a capacitor produces a square-wave current output. (A) Bilayer capacitance can be determined by measuring the peak-to-peak magnitude of the square-wave current output $\left(I_{\mathrm{C}}\right)$. (B) A leak in the bilayer is visualized by the triangular ohmic deviation $\left(I_{\mathrm{R}}\right)$ from the ideal square-wave. 
for determining the quality of a bilayer seal (leaks are readily apparent as a triangular deviation from the ideal square-wave output $\left(I_{R}\right.$ in Fig. 22.7)).

\subsection{Inserting pores and adding DNA}

In the case of $\alpha \mathrm{HL}$, there are several ways to insert the pore into a planar bilayer. $\alpha \mathrm{HL}$ is a toxin that assembles spontaneously from water-soluble monomers, so pores can be formed by adding monomeric $\alpha \mathrm{HL}$ directly to the chamber. However, it is often difficult to obtain a single channel by using this approach (many pores tend to insert if the monomer remaining after a single pore has formed is not removed by perfusion), and we also find that the $\alpha \mathrm{HL}$ pores formed from monomers have substantial pore-to-pore variability (discussed below). We therefore prefer to use preoligomerized protein in a detergent-solubilized form (e.g., after extraction from an SDS-polyacrylamide gel as described below). Typically $\sim 0.2 \mu \mathrm{l}$ of SDS-solubilized heptamer $\left(\sim 1 \mathrm{ng} \mu \mathrm{l}^{-1}\right)$ is manually ejected from a pipette very close to the bilayer beneath the surface of the solution in the cis compartment. The solution in the compartment is then stirred gently with a small magnetic stirrer bar until a single insertion event is observed. Electrical recordings are noisy while stirring, as the changing magnetic field produced by the rotating stirrer and stirrer bar induces currents in the electrodes, and stirring is discontinued for the rest of the experiment, unless additions are made to a compartment. Although the protein concentration can be reduced to improve the chances of obtaining a single insertion event, this often requires waiting a considerable length of time. Alternatively, a higher concentration of protein can be added to reduce the time to insertion, followed by prompt perfusion (see below) to remove free protein.

Two other methods of inserting protein employed in our laboratory are vesicle fusion (better suited to proteins that are unstable in detergent) (Morera et al., 2007) and direct introduction with probes (Holden and Bayley, 2005; Holden et al., 2006), which is also suited to unstable proteins or proteins of which only small quantities are available.

DNA, RNA, or other analytes are added directly to the chamber solutions from stocks (typically $100 \mu M$ in double-distilled water $\left(\mathrm{ddH}_{2} \mathrm{O}\right)$ or $10 \mathrm{~m} M$ Tris-HCl, $100 \mu M$ EDTA, $\mathrm{pH}$ 8.0) by pipet. Mixing is achieved by stirring the chamber solution for up to $1 \mathrm{~min}$ (using a $5 \mathrm{~mm}$ stirrer bar in the bottom of the compartment). Depending on the experiment, we typically add oligonucleotides to the $1 \mathrm{ml}$ compartment solution from $100 \mu M$ stocks to give final concentrations of $10 \mathrm{n} M$ to $2 \mu M$. The electrode compartments may represent an appreciable dead volume (e.g., $5 \%$ of the total volume), which must be taken into account for quantitative work. Better still, the concentration of a DNA or RNA in a compartment should be checked after an experiment, for example, by UV spectrometry. 


\subsection{Perfusion}

We use perfusion to remove free protein from the bulk solution once a single pore has inserted, and to change the solution conditions or analytes in the system while retaining the same pore in the bilayer. We perfuse our devices by manual pipetting (removing some solution and replacing it with fresh solution) or with push-pull syringe drivers (e.g., PHD 2000, Harvard Apparatus) that exchange the solution at rates of $\sim 1 \mathrm{ml} \mathrm{min}^{-1}$. It should be noted that solution-filled perfusion tubing entering the Faraday cage acts as an antenna and picks up radiative noise that can prevent useful recording while the perfusion equipment is connected. If this is a problem, drip-feed perfusion can be employed, where the air pocket breaks the electrical continuity in the tubing.

\section{NANOPORES}

\subsection{Nanopore preparation}

While monomeric $\alpha \mathrm{HL}$ can be obtained commercially, we recommend the use of heptamers carefully prepared in the laboratory. This is of course essential for heteroheptamers with defined subunit combinations (Miles et al., 2002), but we have also found that preassembled homoheptamers give more consistent results than monomers in bilayer experiments.

In our laboratory, $\alpha \mathrm{HL}$ homoheptamers used in single-channel recording experiments are usually prepared from $\alpha \mathrm{HL}$ monomers expressed by in vitro transcription and translation (IVTT). Heptamers are formed by incubating the monomers with rabbit red blood cell membranes and purified by SDS-PAGE (Cheley et al., 1999). The concentration of heptamer after purification is typically $\sim 1 \mathrm{ng} \mu \mathrm{l}^{-1}$. Alternatively, if a higher concentration of protein is required (e.g., for a protein that inserts poorly; Maglia et al., 2009a), $\alpha$ HL monomers can be expressed in Escherichia coli or Staphylococcus aureus bacterial expression systems (Cheley et al., 1997). In these cases, monomers are purified by ion exchange chromatography before incubation with a surfactant $(6.25 \mathrm{~m} M$ DOC; Bhakdi et al., 1981; Tobkes et al., 1985) to trigger the heptamerization process. Heptamers are then separated from monomers by size-exclusion chromatography (Cheley et al., 1997). These procedures are more laborious, but $\alpha \mathrm{HL}$ heptamers at concentrations of $1-5 \mathrm{mg} \mathrm{ml}^{-1}$ can be obtained.

\subsection{Nanopore storage}

$\alpha \mathrm{HL}$ heptamers are usually stored at $-80{ }^{\circ} \mathrm{C}$ in $10 \mathrm{mM}$ Tris- $\mathrm{HCl}$ buffer at $\mathrm{pH}$ 8.0, containing $100 \mu \mathrm{M}$ EDTA. Heptamers prepared from monomers produced from bacterial expression systems will also contain surfactants 
(usually 1.25 $\mathrm{mM}$ DOC), while heptamers prepared from $\alpha \mathrm{HL}$ monomers obtained by IVTT are likely to contain small amounts of polyacrylamide and SDS that are carried over from the SDS-PAGE purification. Polyacrylamide can be removed by using a small size-exclusion column (e.g., P6 Micro Bio-Spin chromatography columns, Bio-Rad), but it usually does not interfere with single-channel recording experiments.

To obtain single channels, protein solutions obtained after IVTT expression, assembly, and electrophoretic purification are usually diluted 10 -fold in buffer or $\mathrm{ddH}_{2} \mathrm{O}$, and $0.2 \mu \mathrm{l}$ is added to the buffer in the planar bilayer chamber. At this point, residual SDS is well below its critical micelle concentration (CMC). During an experiment, solutions containing $\alpha \mathrm{HL}$ proteins are kept on ice. $\alpha \mathrm{HL}$ preparations can be stored at $4{ }^{\circ} \mathrm{C}$ for shortterm use (less than a week), but the protein slowly loses activity. Multiple freeze/thaw cycles also reduce protein activity. When a reactive group is present (e.g., an oxidation sensitive cysteine residue), the protein must be handled with particular care and long-term storage at $-80{ }^{\circ} \mathrm{C}$ is usually limited to a few months.

\subsection{Measurements with nanopores}

Purified WT heptamers form pores that have a high unitary conductance ( $\sim \mathrm{nS}$ at $+100 \mathrm{mV}$ in $1 \mathrm{M} \mathrm{KCl}$ solution). WT- $\alpha \mathrm{HL}$ pores show no gating events (openings and closings of the pore), unless the applied potential is high (more than $\pm 180 \mathrm{mV}$ ), and even then the events are rare (generally less than $\left.1 \mathrm{~min}^{-1}\right)$. Pore-to-pore variation of the unitary conductance is generally within $5 \%$ of the mean. However, very occasionally ( $<5 \%$ of the cases), the pores show a high level of gating or have a dramatically reduced conductance. These cases probably arise from misfolded or misassembled heptamers and are discarded. $\alpha \mathrm{HL}$ monomers, rather than purified heptamers, can also be used in single-channel recordings. However, a much greater number of the pores formed from monomers (from $20 \%$ to $50 \%$, depending on the batch) show a reduced conductance or gating events. The use of heptamers purified by SDS-PAGE is therefore recommended. Over the course of long experiments $(>30 \mathrm{~min})$, the open pore current can drift due to evaporation of the solutions or exhaustion of the $\mathrm{Ag} / \mathrm{AgCl}$ electrodes. It is recommended, therefore, always to use agarose bridges around the electrodes and to minimize the surface area of the solutions. If lids are used, care must be taken to prevent a short circuit through a film of electrolyte. Layers of oil can be placed on the surfaces of the chamber solutions, but then a complete clean-up will be required if the bilayer is reformed.

The $\alpha \mathrm{HL}$ pore can be altered by site-directed mutagenesis to give improvements in $f$ and $I_{\mathrm{B}}$. Alteration of the lumen of the $\alpha \mathrm{HL}$ pore by site-directed mutagenesis generally produces nanopores that have similar unitary conductance $\left(I_{\mathrm{O}}\right)$ values to that of WT- $\alpha \mathrm{HL}(\mathrm{Gu}$ et al., 2001; 
Stoddart et al., 2009). Additional charges in the barrel, however, can alter the unitary conductance and rectification properties (Maglia et al., 2008), while the introduction of aromatic residues near the constriction (e.g., M113W and M113Y), or positively charged residues near the trans entrance (e.g., T129R and T125R) can produce pores that show a high frequency of gating (M. Rincon-Restrepo, unpublished data). In some cases, the gating events observed with nanopores that have additional positive charge in the barrel might be due to the binding of contaminants to the protein pore (Cheley et al., 2002) as they are more frequent at low salt concentrations when the charges within the pore are less well screened.

\subsection{Nanopore stability}

$\alpha \mathrm{HL}$ heptamers in bilayers are stable under extreme conditions of salt concentration, temperature (Kang et al., 2005), $\mathrm{pH}$ (Gu and Bayley, 2000; Maglia et al., 2009b), and in the presence of denaturants (Japrung et al., 2010). Pores can insert into bilayers and remain open over a wide range of ionic strengths (from 0.001 to $4 \mathrm{M} \mathrm{KCl}$ ). Throughout this range, the conductance of the pore varies linearly with the ionic concentration of the solution, except at very low salt concentrations where there is a small deviation from linearity (Oukhaled et al., 2008).

Electrical recordings of $\alpha \mathrm{HL}$ pores have been carried out from 4 to $93{ }^{\circ} \mathrm{C}$ (Kang et al., 2005). Over this range, the conductance of the pore increases roughly linearly, largely reflecting the temperature dependence of the conductivity of the electrolyte. DNA translocation experiments are usually carried out at room temperature, but lower temperatures can be used to reduce the speed of DNA translocation through the pore, by an order of magnitude over a range of $25^{\circ} \mathrm{C}$ at $+120 \mathrm{mV}$ (Meller et al., 2000), which is most likely an effect of the lowered viscosity. High temperatures might be useful for denaturing DNA during translocation experiments.

Current recordings from $\alpha \mathrm{HL}$ pores in symmetric solutions have been performed from $\mathrm{pH} 4$ to 13 (Gu and Bayley, 2000; Maglia et al., 2009b). However, the rate of insertion of preassembled heptamers decreases dramatically at $\mathrm{pH}$ values greater than 11 and at $\mathrm{pH}>11.7 \alpha \mathrm{HL}$ can no longer be transferred into planar lipid bilayers. $\mathrm{CD}$ and fluorescence experiments revealed that the cap domain of the protein is unfolded in $0.3 \%(\mathrm{w} / \mathrm{v})$ SDS at $\mathrm{pH} 12$, suggesting that correct folding of the cap is important for the insertion of $\alpha \mathrm{HL}$ heptamers. Once in lipid bilayers, however, $\alpha \mathrm{HL}$ pores appear to be more stable than in SDS solution and there is no evidence to suggest that the protein unfolds within the $\mathrm{pH}$ range tested. Therefore, to examine $\alpha \mathrm{HL}$ at $\mathrm{pH}>11$, the pores must be reconstituted at lower $\mathrm{pH}$ and the $\mathrm{pH}$ of the solution brought to the desired $\mathrm{pH}$ by adding small portions of $1 \mathrm{M} \mathrm{KOH}$ with stirring. The $\mathrm{pH}$ of the cis compartment (ground) can be monitored by using a $\mathrm{pH}$ electrode. However, measurement of the $\mathrm{pH}$ in 
the trans compartment provokes breaking of the bilayer, unless the trans electrode is removed or a conducting bridge is first formed with a Pt wire between the two compartments.

$\alpha \mathrm{HL}$ pores are also stable in high concentrations of denaturants (e.g., up to $8 M$ urea), which has been used, for example, to investigate the translocation of unfolded polypeptides (Oukhaled et al., 2007) or to reduce the secondary structure of DNA for translocation (Japrung et al., 2010). Since the insertion of $\alpha \mathrm{HL}$ occurs only at concentrations of urea lower than $3 \mathrm{M}$, higher concentrations of denaturants are attained by replacing the buffer after a pore has inserted into a planar bilayer.

\section{Materials}

\subsection{Buffer components}

Typically, DNA translocation experiments are carried out in $1 \mathrm{M} \mathrm{KCl}$. Because of possible contaminants, the $\mathrm{KCl}$ and other buffer components should be of the highest possible purity. We use $\mathrm{KCl}$ from Fluka (catalog no. 05257 ) which contains less than $0.0005 \%$ of trace metals.

\subsection{Handling of DNA and RNA}

In many experiments, synthetic DNAs and RNAs of 50-100 nt are used. The capture of these nucleic acids is inefficient (e.g., $\sim 4 \mathrm{~s}^{-1} \mu M^{-1}$ at $+120 \mathrm{mV}$ with WT- $\alpha \mathrm{HL}$ ) (Henrickson et al., 2000; Maglia et al., 2008; Meller, 2003; Nakane et al., 2002). Therefore, DNA or RNA is usually presented at concentrations of $>100 \mathrm{n} M$ and the use of small chambers can help conserve materials (Akeson et al., 1999). Nucleic acids, especially RNA, should be manipulated under nuclease-free conditions. Materials including water, tips, and tubes should be autoclaved prior to use and the experimental area should be cleaned with a product such as RNaseZap (Ambion), to inactivate RNAse. RNaseZap may also be used on the chamber provided it is thoroughly rinsed afterward. Purified RNA can be stored in $50 \%(\mathrm{v} / \mathrm{v})$ formamide, which is known to protect RNA from degradation (Chomczynski, 1992).

\subsection{Short single-stranded DNA or RNA}

Several companies, such as ATDBio, Sigma Genosys, RNAeasy kit, Integrated DNA Technologies, and Bio-Synthesis, carry out the custom synthesis of nucleic acids of up to $200 \mathrm{nt}$ in length for ssDNA and up to 50 nt for RNA at the micromole level. An advantage of using synthetic oligonucleotides is that they can be chemically modified at their $5^{\prime}$ or $3^{\prime}$ 
ends and that additional bases, such as $5^{\prime}$-methylcytosine, can be incorporated at specific sites. Pure oligonucleotides are essential for nanopore investigations and therefore they are usually desalted by the company, purified by HPLC or PAGE as appropriate for the length, and delivered as dried ethanol precipitates. We have also purified desalted short ssDNA (50$100 \mathrm{nt})$ and ssRNA (<50 nt) from Sigma Genosys by denaturing, $7 \mathrm{M}$ urea, $8 \%$ polyacrylamide gel electrophoresis (PAGE). After electrophoresis, the ssDNA and ssRNA are stained with ethidium bromide $\left(10 \mu \mathrm{g} \mathrm{ml}^{-1}\right)$ and visualized under a UV transilluminator 2000 (Bio-Rad). The desired band of polyacrylamide is cut out and crushed in water $(100 \mu \mathrm{l})$. The gel is separated from the eluted ssDNA by using P6 Micro-Spin chromatography columns (Bio-Rad). Purity is checked by analytical PAGE.

\subsection{Long single-stranded DNA}

The preparation of long ssDNA molecules $(>200 \mathrm{nt})$ is usually achieved by using asymmetric PCR. dsDNA templates of the desired length (200-8000 bp) and sequence are prepared by cutting a plasmid DNA with the requisite restriction enzymes. The desired dsDNA is purified from the plasmid DNA by PAGE. The template (e.g., $\sim 0.4 \mu \mathrm{g}$ of a $1 \mathrm{~kb}$ fragment) is then mixed with a 50 - to 100 -fold excess of a single synthetic primer that is complementary to a specific sequence in the dsDNA template, and 95 asymmetric PCR cycles are carried out (Screaton et al., 1993). Since only one primer is present, ssDNA is generated, which is then separated from the dsDNA template by PAGE. Alternatively, the primer that is used in the asymmetric PCR can be biotinylated, and the ssDNA can be purified by chromatography with immobilized streptavidin (Kai et al., 1997; Pagratis, 1996). Asymmetric PCR produces only one copy of the template in each cycle and the final yield of ssDNA is generally poor (e.g., $\sim 0.2 \mu \mathrm{g}$ for the $1 \mathrm{~kb}$ template). The DNA is purified by using a $0.8 \%$ low-melt agarose gel.

In an alternative method, a dsDNA template $(0.4 \mu \mathrm{g})$ is amplified in 35 PCR cycles by using two primers, one of which is protected at the $5^{\prime}$ end (e.g., with a covalently attached biotin). In this case, amplification is exponential. After 35 cycles, the resulting dsDNA $(\sim 25 \mu \mathrm{g}$ from a $50 \mu \mathrm{l}$ reaction) is desalted by using a gel filtration column (Micro Bio-Spin P30 Column, Bio-Rad), and concentrated to 300-500 ng $\mu \mathrm{l}^{-1}$ with a centrifugal vacuum concentrator (SpeedVac, Savant). Then, to obtain ssDNA, the dsDNA is incubated with $\lambda$-exonuclease $\left(\sim 2 \mathrm{U} \mu \mathrm{g}^{-1}\right.$ of DNA) for $3 \mathrm{~h}$ at $37^{\circ} \mathrm{C}$, which digests the unprotected DNA strand. After further purification by PAGE, up to $2 \mu \mathrm{g}$ of ssDNA are obtained from $5 \mu \mathrm{g}$ of dsDNA. 


\subsection{Long RNA preparation}

Long RNA molecules can be prepared by transcribing a dsDNA template with an RNA polymerase. RNA molecules up to $8000 \mathrm{nt}$ long can be synthesized. Several companies including Promega and Ambion produce in vitro transcription (IVT) kits. For example, the T7 RiboMAX ${ }^{\mathrm{TM}}$ Express Large Scale RNA Production System kit (Promega) contains materials sufficient for 12 reactions and can synthesize up to $5 \mu \mathrm{g}$ of RNA per reaction. When using this kit, the dsDNA template must contain the T7 promoter sequence that is recognized by T7 RNA polymerase. A typical reaction contains linear dsDNA template $(8 \mu \mathrm{l}, \sim 4 \mu \mathrm{g}), 2 \times$ buffer $(20 \mu \mathrm{l}$, with rNTPs), RNase-free water $(10 \mu \mathrm{l})$, and T7 RNA polymerase $(2 \mu \mathrm{l})$. The mixture is incubated at $37^{\circ} \mathrm{C}$ for $1 \mathrm{~h}$ to produce the desired RNA and then the dsDNA template is digested with RQ1 RNase-free DNase $(4 \mu \mathrm{l}$,

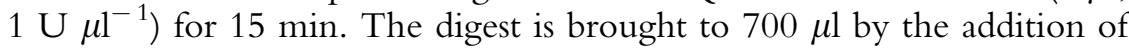
RNase-free water (up to $100 \mu \mathrm{l}$, RNAeasy kit), buffer RLT (350 $\mu$, RNAeasy kit) and ethanol (250 $\mu \mathrm{l}, 96-100 \%)$. The sample is then loaded onto a RNase Mini spin column (RNAeasy kit) and washed twice with buffer RPE (500 $\mu$ l, RNAeasy kit). The desired RNA is eluted with "double sterile" water (50 $\mu$ l, RNAeasy kit). The RNA can be purified in a $5 \%$ or $8 \%$ polyacrylamide gel, or in a $0.8 \%$ agarose gel.

\subsection{Short dsDNA preparation}

dsDNA can be prepared by mixing equimolar amounts of two synthetic complementary ssDNAs in exonuclease I buffer $(67 \mathrm{mM}$ glycine- $\mathrm{KOH}$, $6.7 \mathrm{mM} \mathrm{MgCl}, 10 \mathrm{mM}$ 2-mercaptoethanol, $\mathrm{pH}$ 9.4; New England BioLabs). To facilitate the annealing process, the temperature is brought to $95{ }^{\circ} \mathrm{C}$ for $1 \mathrm{~min}$ and then decreased stepwise to room temperature. At around the calculated annealing temperature (www.basic.northwestern. edu/biotools/oligocalc.html), the temperature is decreased in small steps (e.g., $2{ }^{\circ} \mathrm{C}$, each held for $1 \mathrm{~min}$ ). Excess ssDNA is digested by incubation with E. coli exonuclease I (20 U, New England BioLabs) for $30 \mathrm{~min}$ at $37^{\circ} \mathrm{C}$. The dsDNA is ethanol precipitated by first adding 0.1 volumes of $3.0 \mathrm{M}$ sodium acetate at $\mathrm{pH} \mathrm{5.2}$, and then 2.5 volumes of cold $95 \%(\mathrm{v} / \mathrm{v})$ ethanol. The mixture is left at $-20{ }^{\circ} \mathrm{C}$ for $1 \mathrm{~h}$ and then centrifuged at $25,000 \times g$ for $20 \mathrm{~min}$. The white pellet is washed several times with cold $95 \%$ (v/v) ethanol and after drying taken up in $10 \mathrm{mM}$ Tris- $\mathrm{HCl} 100 \mu \mathrm{M}$ EDTA, pH 7.5. Residual low molecular weight contaminants can be removed by passing the DNA solution (maximum $75 \mu \mathrm{l}$ ) through a BioSpin ${ }^{\circledR} 30$ column (Bio-Rad). The purity of dsDNA is checked by PAGE by using dyes that stain both single- and double-stranded nucleic acids, for example, Stains-All (Sigma-Aldrich). 


\section{Data Acquisition and Analysis}

\subsection{Data digitization}

The ionic current that flows through a nanopore can be measured by using commercial instruments such as the Axopatch 200B patch-clamp amplifier. These instruments transform the continuous analog current signal into an analog voltage signal, which is then fed to a digitizer that converts it into binary numbers with finite resolution (digitization). The digitizer is connected to a computer that converts and displays the digitized current information. We use 132x or 1440A 16-bit digitizers (Molecular Devices), with a dynamic input range of $\pm 10 \mathrm{~V}$, which divides the signal into $2^{16}(65,536)$ values (bins), providing a resolution of $0.305 \mathrm{mV} / \mathrm{bin}\left(20 \mathrm{~V} / 2^{16}\right)$. If no output gain is applied, this corresponds to a dynamic range of $\pm 10 \mathrm{nA}$ and a resolution of $0.305 \mathrm{pA} / \mathrm{bin}$. However, the output gain can be changed (by up to 500-fold) to increase the resolution (decreased bin width), at the expense of dynamic range. Typically, when measuring the translocation of DNA molecules through a single $\alpha \mathrm{HL}$ nanopore the output gain is set to at least $10 \times$, which corresponds to a dynamic range of $1 \mathrm{nA}$ and a resolution of $0.0305 \mathrm{pA} / \mathrm{bin}$.

\subsection{Filtering and sampling}

The signal collected by the amplifier must be filtered to remove highfrequency electrical noise. The most common filtering is low-pass filtering, which limits the bandwidth of the data by eliminating signals above the corner frequency (or cutoff frequency) of the filter. Bessel filters, rather than Butterworth filters, are usually applied for time-domain analyses, as Bessel filters are better at preserving the shape of the single-channel response (The Axon Guide) (Silberberg and Magleby, 1993). It is important to select the correct corner frequency and in order to keep errors in estimates of current levels to $<3 \%$, the applied filter cutoff should be greater than five times the inverse of the mean event time (Silberberg and Magleby, 1993). For example, the most probable translocation time for a 92-nt DNA strand through the WT- $\alpha \mathrm{HL}$, at $+120 \mathrm{mV}$ in $1 \mathrm{M} \mathrm{KCl}, 25 \mathrm{mM}$ Tris $-\mathrm{HCl}$ at $\mathrm{pH} 8$, is $0.141 \mathrm{~ms}$ (Maglia et al., 2008). Therefore, the cutoff frequency should be $\sim 35 \mathrm{kHz}$ or higher (Fig. 22.8A). Over-filtering of the signal can lead to inaccurate estimates of $I_{\mathrm{B}}$ and $t_{\mathrm{t}}$ (Fig. 22.8B). As well as the appropriate filtering rate, it is important to select the correct sampling rate. The Nyquist Sampling Theorem states that the sampling rate should be twice the cutoff frequency of the applied filter (The Axon Guide). In practice, however, it is preferable to oversample (i.e., sample at a rate that exceeds the Nyquist minimum) (Sakmann and Neher, 1995). A sampling rate of 10 times that of 


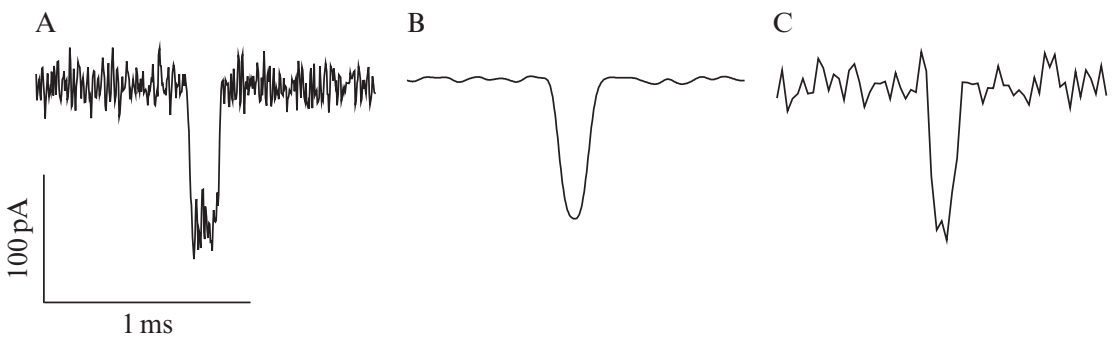

Figure 22.8 The effects of the filter cutoff frequency and sampling rate on the recording of DNA translocation events. The $t_{\mathrm{t}}$ for each event is $\sim 0.14 \mathrm{~ms}$ suggesting a filter cutoff of $\sim 35 \mathrm{kHz}$ (see the text). (A) Signal filtered at $40 \mathrm{kHz}$ with a low-pass 8-pole Bessel filter, and sampled at $250 \mathrm{kHz}$. The filtering and sampling allow faithful reproduction of the translocation event. (B) The event shown in panel A is filtered at $5 \mathrm{kHz}$. The sampling rate remains $250 \mathrm{kHz}$. $I_{\mathrm{B}}$ and $t_{\mathrm{t}}$ can no longer be determined accurately. (C) In this case, although the correct level of filtering has been applied $(40 \mathrm{kHz})$, the signal is sampled at the suboptimal rate of $40 \mathrm{kHz}$.

the cutoff frequency of the filter is desirable, but five times the cutoff frequency is usually sufficient.

\subsection{Acquisition protocols}

The software we use to collect and display the current signals is Clampex from Molecular Devices; however, other software such as QuB (www.qub. buffalo.edu) and WinEDR (http://spider.science.strath.ac.uk/sipbs/page. php?show=software_winEDR) can be used. Clampex can also control the $132 \mathrm{x}$ or $1440 \mathrm{~A}$ digitizer to apply a potential through the amplifier (see below). Although Clampex has five data acquisition modes, the most commonly used during DNA translocation experiments, are the "Gap Free," "Variable-Length Events," and "Episodic Stimulation" modes.

In the Gap Free protocol, data are passively and continuously digitized, displayed, and saved. There are no interruptions to the data record, which make it a useful protocol to use when preparing data for publication. However, it should not be used routinely when acquiring with a high sampling rate, or for a long period of time, as the file sizes can become very large (e.g., acquiring at $250 \mathrm{kHz}$ for $1 \mathrm{~h}$ will produce a $1.7 \mathrm{~GB}$ file).

The Variable-Length Events protocol is ideal for collecting data from a fully characterized system where the frequency of events is very low, and there are long periods of inactivity. Data are visualized as in the gap free protocol, but are acquired only for as long as an input signal has passed a threshold level (which is set manually), so only the "events" and small sections on either side of them are recorded. The file sizes are therefore more manageable, although the data record is interrupted. 

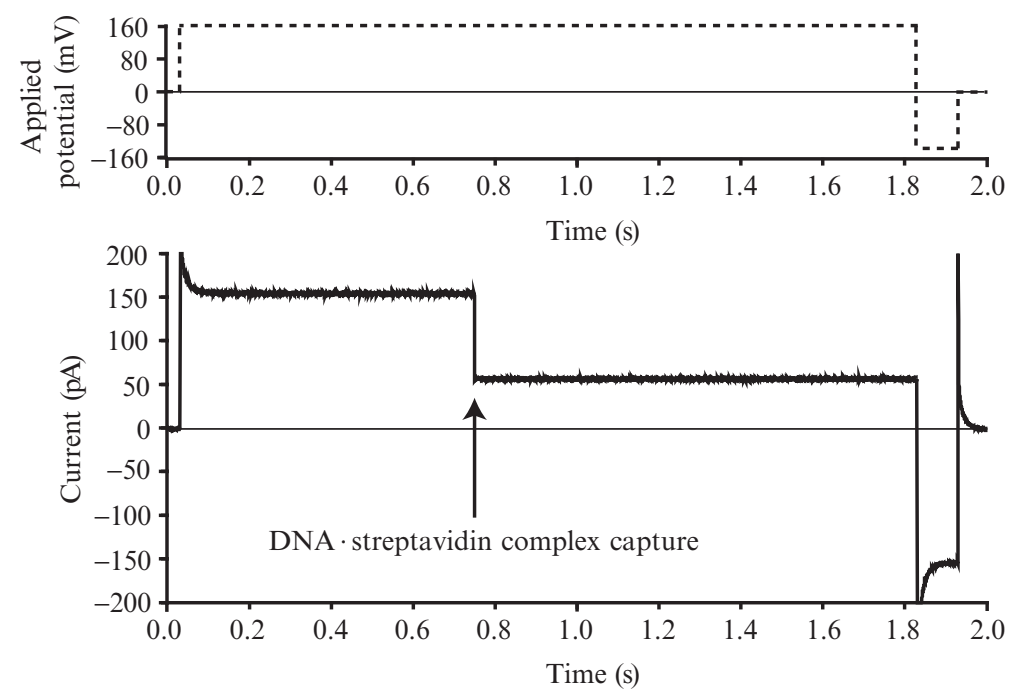

Figure 22.9 Episodic stimulation mode allows both an output voltage (dashed line) to be applied, while simultaneously recording the resulting changes in ionic current. In this example, a positive potential bias of $+160 \mathrm{mV}$ is applied to the system, resulting in an open pore current level of $\sim 160 \mathrm{pA}$. Under the applied potential, a DNA molecule is driven into the pore and becomes immobilized (through a terminal biotin -streptavidin complex), and the current level is reduced. The potential bias is reversed $(-140 \mathrm{mV})$ and the DNA molecule is ejected. The bias is then removed. The protocol can be repeated numerous times.

The Episodic Stimulation protocol can be used to output a voltage signal from the digitizer, which can be applied to the bilayer system, while simultaneously acquiring the resulting current signal. This mode is used to apply voltage steps (e.g., when producing $I-V$ curves) or voltage ramps (Dudko et al., 2007). It can also be used when it is laborious to apply different voltages manually with the patch-clamp amplifier, for example, when studying the repeated immobilization of DNA molecules inside the $\alpha \mathrm{HL}$ pore. In this case, a voltage bias can be applied, for a fixed amount of time, to drive a DNA -streptavidin complex into the pore. The bias is then reversed to eject the molecule from the pore (Fig. 22.9) (Purnell et al., 2008; Stoddart et al., 2009, 2010). The changes in the current level that occur as a result of the voltage protocol are simultaneously acquired. The protocol can be repeated hundreds of times per run and therefore many DNA blockades can be recorded. The output waveform can be set manually to apply different voltage steps, for different times, and it does not have to be the same for each sweep during a run.

\subsection{Analysis of single DNA/RNA molecules}

The current traces recorded by the digitizer can be analyzed by using the "single-channel search" option in the Clampfit software package (Molecular Devices). In doing so, the user must assign the value of the open pore current 


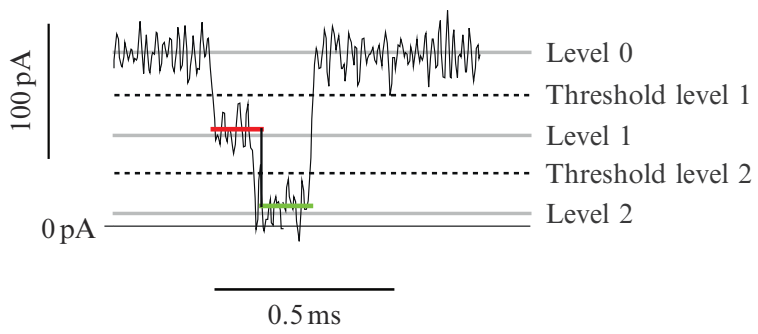

Figure 22.10 Typical DNA translocation event analyzed by the Clampfit software. Levels 0,1 , and 2 are set manually and the software automatically assigns data points to level 1 (red line) or level 2 (green line).

(level 0) and a second level (level 1) that corresponds to the blocked pore level. If a DNA molecule provokes several types of current blockade, of differing amplitude, additional levels can be assigned (levels $2,3, \ldots$, etc.). Every time the ionic current crosses a threshold (the half distance between two levels), the software recognizes it as an "event"( Fig. 22.10) and records its characteristics such as the mean amplitude, the dwell time, and the interevent interval in a results window. Generally, for short DNA molecules, the average current amplitudes, dwell times, and interevent intervals of numerous events are plotted as histograms. Gaussian fits to the events histogram of the amplitudes and dwell times are used to determine $I_{\mathrm{B}}$ and $t_{\mathrm{P}}$, respectively; while $\bar{t}_{\mathrm{ON}}$ is determined from an exponential fit to the histogram of the interevent intervals. The dwell times $\left(t_{\mathrm{D}}\right)$ are described by a Gaussian distribution with an exponential tail; the peak of the Gaussian $\left(t_{\mathrm{P}}\right)$ is generally used to describe the most likely dwell time, which often represents the translocation time, $t_{\mathrm{t}}$ (Meller et al., 2000). In the case of DNA strands immobilized within a nanopore, $I_{\mathrm{B}}$ values are the only meaningful features of the events (Ashkenasy et al., 2005; Purnell and Schmidt, 2009; Stoddart et al., 2009).

\section{REFERENCES}

Akeson, M., Branton, D., Kasianowicz, J. J., Brandin, E., and Deamer, D. W. (1999). Microsecond time-scale discrimination among polycytidylic acid, polyadenylic acid and polyuridylic acid as homopolymers or as segments within single RNA molecules. Biophys. J. 77, 3227-3233.

Ashkenasy, N., Sánchez-Quesada, J., Bayley, H., and Ghadiri, M. R. (2005). Recognizing a single base in an individual DNA strand: A step toward nanopore DNA sequencing. Angew. Chem. Int. Ed. Engl. 44, 1401-1404.

Astier, Y., Kainov, D. E., Bayley, H., Tuma, R., and Howorka, S. (2007). Stochastic detection of motor protein-RNA complexes by single-channel current recording. ChemPhysChem 8, 2189-2194. 
Bayley, H. (2006). Sequencing single molecules of DNA. Curr. Opin. Chem. Biol. 10, 628-637.

Bayley, H., and Cremer, P. S. (2001). Stochastic sensors inspired by biology. Nature 413, 226-230.

Bayley, H., Cronin, B., Heron, A., Holden, M. A., Hwang, W., Syeda, R., Thompson, J., and Wallace, M. (2008a). Droplet interface bilayers. Mol. BioSyst. 4, 1191-1208.

Bayley, H., Luchian, T., Shin, S.-H., and Steffensen, M. B. (2008b). Single-molecule covalent chemistry in a protein nanoreactor. In "Single Molecules and Nanotechnology," (R. Rigler and H. Vogel, eds.), pp. 251-277. Springer, Heidelberg.

Bezrukov, S. M., and Kasianowicz, J. J. (1993). Current noise reveals protonation kinetics and number of ionizable sites in an open protein ion channel. Phys. Rev. Lett. 70, 2352-2355.

Bhakdi, S., Füssle, R., and Tranum-Jensen, J. (1981). Staphylococcal $\alpha$-toxin: Oligomerization of hydrophilic monomers to form amphiphilic hexamers induced through contact with deoxycholate micelles. Proc. Natl. Acad. Sci. USA 78, 5475-5479.

Bonthuis, D. J., Zhang, J., Hornblower, B., Mathe, J., Shklovskii, B. I., and Meller, A. (2006). Self-energy-limited ion transport in subnanometer channels. Phys. Rev. Lett. 97, 128104.

Branton, D., Deamer, D. W., Marziali, A., Bayley, H., Benner, S. A., Butler, T., Di Ventra, M., Garaj, S., Hibbs, A., Huang, X., Jovanovich, S. B., Krstic, P. S., et al. (2008). The potential and challenges of nanopore sequencing. Nat. Biotechnol. 26, 1146-1153.

Butler, T. Z., Gundlach, J. H., and Troll, M. (2007). Ionic current blockades from DNA and RNA molecules in the alpha-hemolysin nanopore. Biophys. J. 93, 3229-3240.

Butler, T. Z., Pavlenok, M., Derrington, I. M., Niederweis, M., and Gundlach, J. H. (2008). Single-molecule DNA detection with an engineered MspA protein nanopore. Proc. Natl. Acad. Sci. USA 105, 20647-20652.

Cheley, S., Malghani, M. S., Song, L., Hobaugh, M., Gouaux, J. E., Yang, J., and Bayley, H. (1997). Spontaneous oligomerization of a staphylococcal $\alpha$-hemolysin conformationally constrained by removal of residues that form the transmembrane $\beta$ barrel. Protein Eng. 10, 1433-1443.

Cheley, S., Braha, O., Lu, X., Conlan, S., and Bayley, H. (1999). A functional protein pore with a "retro" transmembrane domain. Protein Sci. 8, 1257-1267.

Cheley, S., Gu, L.-Q., and Bayley, H. (2002). Stochastic sensing of nanomolar inositol 1,4,5-trisphosphate with an engineered pore. Chem. Biol. 9, 829-838.

Chomczynski, P. (1992). Solubilization in formamide protects RNA from degradation. Nucleic Acids Res. 20, 3791-3792.

Clarke, J., Wu, H., Jayasinghe, L., Patel, A., Reid, S., and Bayley, H. (2009). Continuous base identification for single-molecule nanopore DNA sequencing. Nat. Nanotechnol. 4, 265-270.

Cockroft, S. L., Chu, J., Amorin, M., and Ghadiri, M. R. (2008). A single-molecule nanopore device detects DNA polymerase activity with single-nucleotide resolution. J. Am. Chem. Soc. 130, 818-820.

Deamer, D. W., and Branton, D. (2002). Characterization of nucleic acids by nanopore analysis. Acc. Chem. Res. 35, 817-825.

Dekker, C. (2007). Solid-state nanopores. Nat. Nanotechnol. 2, 209-215.

Dudko, O. K., Mathe, J., Szabo, A., Meller, A., and Hummer, G. (2007). Extracting kinetics from single-molecule force spectroscopy: Nanopore unzipping of DNA hairpins. Biophys. J. 92, 4188-4195.

Gillis, K. D. (1995) In “Techniques for membrane capacitance measurements," (B. Sakmann, and E. Neher, ed), pp. 155, Vol. 2. Plenum, New York. 
Gu, L. Q., and Bayley, H. (2000). Interaction of the non-covalent molecular adapter, b-cyclodextrin, with the staphylococcal $\alpha$-hemolysin pore. Biophys. J. 79, 1967-1975.

Gu, L. Q., Cheley, S., and Bayley, H. (2001). Prolonged residence time of a noncovalent molecular adapter, $\beta$-cyclodextrin, within the lumen of mutant $\alpha$-hemolysin pores. J. Gen. Physiol. 118, 481-494.

Hanke, W., and Schlue, W.-R. (1993). Planar Lipid Bilayers. Academic Press, London.

Henrickson, S. E., Misakian, M., Robertson, B., and Kasianowicz, J. J. (2000). Driven DNA transport into an asymmetric nanometer-scale pore. Phys. Rev. Lett. 85, 3057-3060.

Holden, M. A., and Bayley, H. (2005). Direct introduction of single protein channels and pores into lipid bilayers. J. Am. Chem. Soc. 127, 6502-6503.

Holden, M. A., Jayasinghe, L., Daltrop, O., Mason, A., and Bayley, H. (2006). Direct transfer of membrane proteins from bacteria to planar bilayers for rapid screening by single-channel recording. Nat. Chem. Biol. 2, 314-318.

Hornblower, B., Coombs, A., Whitaker, R. D., Kolomeisky, A., Picone, S. J., Meller, A., and Akeson, M. (2007). Single-molecule analysis of DNA-protein complexes using nanopores. Nat. Methods 4, 315-317.

Howorka, S., Cheley, S., and Bayley, H. (2001). Sequence-specific detection of individual DNA strands using engineered nanopores. Nat. Biotechnol. 19, 636-639.

Hung, W. C., Chen, F. Y., and Huang, H. W. (2000). Order-disorder transition in bilayers of diphytanoyl phosphatidylcholine. Biochim. Biophys. Acta 1467, 198-206.

Japrung, D., Henricus, M., Li, Q., Maglia, G., and Bayley, H. (2010). Urea facilitates the translocation of single-stranded DNA and RNA through the $\alpha$-hemolysin nanopore. Biophys. J. 98, 1856-1863.

Kado, R. T. (1993). Membrane area and electrical capacitance. Methods Enzymol. 221, 273-299.

Kai, E., Sawata, S., Ikebukuro, K., Iida, T., Honda, T., and Karube, I. (1997). Novel DNA detection system of flow injection analysis (2). The distinctive properties of a novel system employing PNA (peptide nucleic acid) as a probe for specific DNA detection. Nucleic Acids Symp. Ser. 321-322.

Kang, X., Gu, L.-Q., Cheley, S., and Bayley, H. (2005). Single protein pores containing molecular adapters at high temperatures. Angew. Chem. Int. Ed. Engl. 44, 1495-1499.

Kasianowicz, J. J., Brandin, E., Branton, D., and Deamer, D. W. (1996). Characterization of individual polynucleotide molecules using a membrane channel. Proc. Natl. Acad. Sci. USA 93, 13770-13773.

Kawano, R., Schibel, A. E., Cauley, C., and White, H. S. (2009). Controlling the translocation of single-stranded DNA through alpha-hemolysin ion channels using viscosity. Langmuir 25, 1233-1237.

Keyser, U. F., Koeleman, B. N., van Dorp, S., Krapf, D., Smeets, R. M. M., Lemay, S. G., Dekker, N. H., and Dekker, C. (2006). Direct force measurements on DNA in a solidstate nanopore. Nat. Phys. 2, 473-477.

Korchev, Y. E., Bashford, C. L., Alder, G. M., Apel, P. Y., Edmonds, D. T., Lev, A. A., Nandi, K., Zima, A. V., and Pasternak, C. A. (1997). A novel explanation for fluctuations of ion current through narrow pores. FASEB J. 11, 600-608.

Krasne, S., Eisenman, G., and Szabo, G. (1971). Freezing and melting of lipid bilayers and the mode of action of nonactin, valinomycin, and gramidicin. Science 174, 412-415.

Lindsey, H., Petersen, N. O., and Chan, S. I. (1979). Physicochemical characterization of 1,2-diphytanoyl-sn-glycero-3-phosphocholine in model membrane systems. Biochim. Biophys. Acta 555, 147-167.

Maglia, G., Rincon Restrepo, M., Mikhailova, E., and Bayley, H. (2008). Enhanced translocation of single DNA molecules through $\alpha$-hemolysin nanopores by manipulation of internal charge. Proc. Natl. Acad. Sci. USA 105, 19720-19725. 
Maglia, G., Heron, A. J., Hwang, W. L., Holden, M. A., Mikhailova, E., Li, Q., Cheley, S., and Bayley, H. (2009a). Droplet networks with incorporated protein diodes show collective properties. Nat. Nanotechnol. 4, 437-440.

Maglia, M., Henricus, M., Wyss, R., Li, Q., Cheley, S., and Bayley, H. (2009b). DNA strands from denatured duplexes are translocated through engineered protein nanopores at alkaline pH. Nano Lett. 9, 3831-3836.

Martin, H., Kinns, H., Mitchell, N., Astier, Y., Madathil, R., and Howorka, S. (2007). Nanoscale protein pores modified with PAMAM dendrimers. J. Am. Chem. Soc. 129, 9640-9649.

Mayer, M., Kriebel, J. K., Tosteson, M. T., and Whitesides, G. M. (2003). Microfabricated teflon membranes for low-noise recordings of ion channels in planar lipid bilayers. Biophys. J. 85, 2684-2695.

Meller, A. (2003). Dynamics of polynucleotide transport through nanometre-scale pores. J. Phys.: Condens. Matter 15, R581-R607.

Meller, A., and Branton, D. (2002). Single molecule measurements of DNA transport through a nanopore. Electrophoresis 23, 2583-2591.

Meller, A., Nivon, L., Brandin, E., Golovchenko, J., and Branton, D. (2000). Rapid nanopore discrimination between single polynucleotide molecules. Proc. Natl. Acad. Sci. USA 97, 1079-1084.

Meller, A., Nivon, L., and Branton, D. (2001). Voltage-driven DNA translocations through a nanopore. Phys. Rev. Lett. 86, 3435-3438.

Miles, G., Bayley, H., and Cheley, S. (2002). Properties of Bacillus cereus hemolysin II: A heptameric transmembrane pore. Protein Sci. 11, 1813-1824.

Miller, C. (ed.), (1986). Ion Channel Reconstitution. Plenum, New York.

Mitchell, N., and Howorka, S. (2008). Chemical tags facilitate the sensing of individual DNA strands with nanopores. Angew. Chem. Int. Ed. Engl. 47, 5565-5568.

Montal, M., and Mueller, P. (1972). Formation of bimolecular membranes from lipid monolayers and study of their electrical properties. Proc. Natl. Acad. Sci. USA 69, 3561-3566.

Morera, F. J., Vargas, G., Gonzalez, C., Rosenmann, E., and Latorre, R. (2007). Ion-channel reconstitution. Methods Mol. Biol. 400, 571-585.

Nakane, J., Akeson, M., and Marziali, A. (2002). Evaluation of nanopores as candidates for electronic analyte detection. Electrophoresis 23, 2592-2601.

Nakane, J., Wiggin, M., and Marziali, A. (2004). A nanosensor for transmembrane capture and identification of single nucleic acid molecules. Biophys. J. 87, 615-621.

Niles, W. D., Levis, R. A., and Cohen, F. S. (1988). Planar bilayer membranes made from phospholipid monolayers form by a thinning process. Biophys. J. 53, 327-335.

Oukhaled, G., Mathé, J., Biance, A.-L., Bacri, L., Betton, J.-M., Lairez, D., Pelta, J., and Auvray, L. (2007). Unfolding of proteins and long transient conformations detected by single nanopore recording. Phys. Rev. Lett. 98, 158101.

Oukhaled, G., Bacri, L., Mathé, J., Pelta, J., and Auvray, L. (2008). Effect of screening on the transport of polyelectrolytes through nanopores. Europhys. Lett. 82, 48003(1-5).

Pagratis, N. C. (1996). Rapid preparation of single stranded DNA from PCR products by streptavidin induced electrophoretic mobility shift. Nucleic Acids Res. 24, 3645-3646.

Peng, H., and Ling, X. S. (2009). Reverse DNA translocation through a solid-state nanopore by magnetic tweezers. Nanotechnology 20, 185101.

Peterman, M. C., Ziebarth, J. M., Braha, O., Bayley, H., Fishman, H. A., and Bloom, D. A. (2002). Ion channels and lipid bilayer membranes under high potentials using microfabricated apertures. Biomed. Microdevices 4, 231-236.

Phillips, R., Ursell, T., Wiggins, P., and Sens, P. (2009). Emerging roles for lipids in shaping membrane-protein function. Nature 459, 379-385. 
Purnell, R. F., Mehta, K. K., and Schmidt, J. J. (2008). Nucleotide identification and orientation discrimination of DNA homopolymers immobilized in a protein nanopore. Nano Lett. 9, 3029-3034.

Purnell, R. F., and Schmidt, J. J. (2009). Discrimination of single base substitutions in a DNA strand immobilized in a biological nanopore. ACS Nano 3, 2533-2538.

Purves, R. D. (1981). Microelectrode Methods for Intracellular Recording and Ionophoresis. Academic Press.

Rhee, M., and Burns, M. A. (2007). Nanopore sequencing technology: Nanopore preparations. Trends Biotechnol. 25, 174-181.

Rincon-Restrepo, M., Mikhailova, E., Bayley, H., and Maglia, G. Controlled translocation of single DNA molecules through engineered protein nanopores. In preparation.

Sakmann, B., and Neher, B. (1995). Single-Channel Recording. Plenum, New York.

Screaton, G. R., Bangham, C. R., and Bell, J. I. (1993). Direct sequencing of single primer PCR products: A rapid method to achieve short chromosomal walks. Nucleic Acids Res. 21, 2263-2264.

Sexton, L. T., Horne, L. P., and Martin, C. R. (2007). Developing synthetic conical nanopores for biosensing applications. Mol. BioSyst. 3, 667-685.

Silberberg, S. D., and Magleby, K. L. (1993). Preventing errors when estimating single channel properties from the analysis of current fluctuations. Biophys. J. 65, 1570-1584.

Song, L., Hobaugh, M. R., Shustak, C., Cheley, S., Bayley, H., and Gouaux, J. E. (1996). Structure of staphylococcal $\alpha$-hemolysin, a heptameric transmembrane pore. Science 274, 1859-1865.

Stoddart, D., Heron, A., Mikhailova, E., Maglia, G., and Bayley, H. (2009). Single nucleotide discrimination in immobilized DNA oligonucleotides with a biological nanopore. Proc. Natl. Acad. Sci. USA 106, 7702-7707.

Stoddart, D., Maglia, G., Mikhailova, E., Heron, A., and Bayley, H. (2010). Multiple baserecognition sites in a biological nanopore-Two heads are better than one. Angew. Chem. Int. Ed. 49, 556-559.

Tobkes, N., Wallace, B. A., and Bayley, H. (1985). Secondary structure and assembly mechanism of an oligomeric channel protein. Biochemistry 24, 1915-1920.

Vercoutere, W., Winters-Hilt, S., Olsen, H., Deamer, D., Haussler, D., and Akeson, M. (2001). Rapid discrimination among individual DNA hairpin molecules at single-nucleotide resolution using an ion channel. Nat. Biotechnol. 19, 248-252.

White, S. (1975). Phase transitions in planar bilayer membranes. Biophys. J. 15, 95-117.

White, S. H. (1986). In "The Physical Nature of Planar Lipid Membranes Ion Channel Reconstitution," (C. Miller, ed.), pp. 3-35. Plenum, New York.

White, S. H., Petersen, D. C., Simon, S., and Yafuso, M. (1976). Formation of planar bilayer membranes from lipid monolayers. A critique. Biophys. J. 16, 481-489.

Wonderlin, W. F., Finkel, A., and French, R. J. (1990). Optimizing planar lipid bilayer single-channel recordings for high resolution with rapid voltage steps. Biophys. J. 58, 289-294. 